\title{
The Cyclical Behavior of Equilibrium Unemployment and Vacancies Across OECD Countries
}

\author{
Pedro S. Amaral \\ Murat Tasci \\ Federal Reserve Bank of Cleveland Federal Reserve Bank of Cleveland
}

February 13, 2013

\begin{abstract}
We show that the inability of a standardly-calibrated stochastic labor search-and-matching model to account for the observed volatility of unemployment and vacancies extends beyond U.S. data to a set of OECD countries - the volatility puzzle is ubiquitous. We also argue that using cross-country data is helpful in evaluating the relative merits of the model alternatives that have appeared in the literature. In illustrating this point, we take the solution proposed in Hagedorn and Manovskii (2008) and show that it continues to predict counterfactually low volatility in labor market variables for countries that exhibit sufficiently low persistence in their estimated productivity processes.
\end{abstract}

JEL Classification: E24, E32, J63, J64.

Keywords: Labor Market, Vacancies, Unemployment, OECD countries. 


\section{Introduction}

Labor market search models as pioneered by Diamond (1982), Mortensen and Pissarides (1994), and Pissarides (2000), henceforth DMP, proved to be very useful in understanding equilibrium unemployment and vacancies as well as the long-run relationship between the two. However, when the model is extended to accommodate aggregate fluctuations, as in Shimer (2005), it fails to generate the observed volatility at business-cycle frequencies by an order of magnitude. In particular, the model requires implausibly large shocks to generate substantial variation in key variables; unemployment, vacancies and market tightness (vacancy to unemployment ratio). This result, sometimes referred to as the "Shimer Puzzle", spurred a large literature on the subject and a scramble for a "solution" to the puzzle.

The availability of vacancy data from the OECD, as well as the work of Elsby, Hobijn, and Sahin (2011) in estimating job-finding and separation rates in a set of OECD countries has created opportunities to analyze labor market fluctuations in the context of a search model across a fairly large set of countries beyond the U.S. This is important because potential solutions to the volatility puzzle identified by Shimer (2005) have been associated with features of the economic environment that might vary, at least to a degree, across countries.

In this paper, we accomplish three goals. First,we document a set of labor market facts at business-cycle frequencies for a cross-section of OECD countries, focusing on unemployment, vacancies, market tightness, and labor productivity. Second, we evaluate the DMP model's ability to replicate business-cycle frequency fluctuations in these variables. We find that all countries in our sample exhibit significantly higher volatility in their labor market variables relative to labor productivity. Moreover, simulations of the DMP model calibrated to country-specific parameter values in a standard Shimer (2005)-like way fail to generate the observed degree of amplification. ${ }^{1}$

Third, and most important, we show how the cross-country scrutiny this data allows can be of help in evaluating the different solutions to the puzzle that have been proposed in the literature. To illustrate this point we take the work of Hagedorn and Manovskii (2008) that shows how calibrating a modified version of Shimer (2005) to target average market tightness and the elasticity of wages with respect to productivity, enables the model to replicate the observed labor market fluctuation in the U.S. This strategy fails to work for some of the countries in our sample.

For countries that exhibit small enough persistence in their estimated productivity process the model continues to deliver significantly smaller volatilities for labor market variables than the data does. The intuition is that everything else being the same, when faced with a positive productivity

\footnotetext{
${ }^{1}$ Zhang (2008) compares the U.S. to Canada, while Miyamoto (2011) and Esteban-Pretel, Ryo, and Ryuichi (2011) focus on the Japanese labor market. Their findings are similar to ours for the respective countries.
} 
shock, more vacancies will be created in an economy where the shock exhibits high persistence as the expected gains from creating such vacancies are higher, everything else being the same.

Our paper is related to a large body of literature that emerged in response to Shimer (2005). In the standard stochastic version of the DMP model, firms respond to a positive productivity shock by creating more vacancies and unemployment duration goes down. This in turn puts upward pressure on wages, absorbing most of the gains in productivity, and thus resulting in insignificant changes in unemployment and vacancies. Several studies proposed wage rigidity as a potential resolution to the puzzle. Shimer (2004), Hall (2005) and Kennan (2010) build on this diagnosis and introduce wage rigidity either exogenously or through an endogenous mechanism, such as asymmetric information. Nonetheless, Mortensen and Nagypál (2007), argue that introducing wage rigidity is not, by itself, sufficient to generate amplification. ${ }^{2}$ Moreover, Pissarides (2009) argues that there is no empirical evidence in favor of wage rigidity over the cycle for newly created matches, which is the important margin for job creation in the canonical DMP model.

Several recent studies also provide mechanisms that can amplify the effects of business cycles on unemployment and vacancies by extending the prototype model in several dimensions and/or approaching the calibration differently. This includes not only the aforementioned Hagedorn and Manovskii (2008), but also Silva and Toledo (2009) that introduces post-match labor turnover costs. While both Costain and Reiter (2008) and Hornstein, Krusell, and Violante (2005) argue that the former study gives rise to counterfactual implications regarding the impact of unemployment subsidies on the equilibrium unemployment rate, the latter study's result depends on a particular constellation of parameter values for separation, hiring and training costs that is hard to justify empirically. There is also a line of research that argues that incorporating on-the-job-search improves the quantitative fit of the model: Krause and Lubik (2006), Nagypál (2006), and Tasci (2007). Finally, Petrosky-Nadeau and Wasmer (2010) argue that financial frictions, in addition to the labor market frictions, can significantly increase the response of vacancies and unemployment to productivity shocks.

While our paper does not provide a direct test of the validity of each channel in a crosscountry context, it is certainly a step in that direction. The ability of most (if not all) mechanisms described above to quantitatively match the volatility of labor market variables is predicated on particular calibrations designed to hit U.S. targets for the most part. We bring in an extra dimension of scrutiny that we hope will prove helpful in distinguishing between all the existent potential explanations. Recent work by Justiniano and Michelacci (2011) has proceeded in exactly this direction. They look at a real business cycle model with search and matching frictions driven by

\footnotetext{
${ }^{2}$ The level of the wage rate must also be such that the future flows of surpluses from new matches are sufficiently small.
} 
several shocks capturing some transmission mechanisms suggested in the literature and estimate it on data from 5 European countries, in addition to the U.S. They find that while technology shocks are able replicate the volatility of labor market variables in the U.S., matching shocks and job destruction shocks play a substantially more important role in European countries.

Our work is also related to a strand of literature that focuses mainly on the role of labor market institutions and policies, in accounting for the differences in unemployment rates across countries in the long-run; in particular between Europe and North America. Nickell, Nunziata, and Ochel (2005) and Blanchard (2006) provide nice surveys of this literature and illustrate how the debate evolved over time and mostly settled on the conclusion that a particular interaction between shocks and labor market institutions can explain both the relatively low average rates of unemployment in Europe early in the post-war period as well as the higher rates observed between 1985 and the early 2000 s. $^{3}$ Our focus, instead, is on the business-cycle frequency variation in the unemployment rate and also involves a discussion of additional labor market variables such as vacancies and market tightness for a similar cross-section of countries.

\section{Data}

We have collected unbalanced data panels at a quarterly frequency on vacancies, unemployment, employment, labor force, and real GDP for a set OECD countries. The proximate sources are the OECD's Economic Outlook Database, the IMF's International Finance Statistics, as well as some direct national sources like Statistics Canada and the Canadian Conference Board for Canadian vacancies, and the Office for National Statistics for U.K. vacancies.

While the data collection process for unemployment, employment, labor force and real GDP is fairly standard across the set of OECD countries we look at, the same cannot be said for the vacancy data. The OECD compiles its vacancy data from a variety of national sources with no harmonized reporting procedures. As a result, this study will not emphasize cross-country comparisons. Instead, we opt for using all the available data we have for each country as opposed to choosing common dates to compare across.

Tables 1 to 3 summarize the data. ${ }^{4}$ Here, the statistics pertain to all the data available for each variable-country pair, as indicated by the columns labeled "Start date" and "End date".

Tables 5 to 17 show the business cycle statistics for each country when we control for the dates by choosing those for the shortest-lived series in that country. ${ }^{5}$ Some patterns emerge that can

\footnotetext{
${ }^{3}$ See Blanchard and Wolfers (2000) and Nickell (1997).

${ }^{4}$ Here, and throughout the paper, productivity is defined as output per worker. Unemployment, vacancies and employment data are in levels and are H-P filtered.

${ }^{5}$ We excluded Belgium and Turkey. For both countries we had only one decade's worth of productivity data.
} 
provide useful clues regarding the DMP model's ability to account for the data.

First, there is a fairly strong positive cross-country correlation between the volatility of productivity and that of both unemployment and vacancies as shown in figures 1 and 2. This suggests that the DMP model with neutral technological shocks as the main driver may be an appropriate framework, or at least one that is not rejected by these data.

Second, there is substantial variation in the degree of correlation between productivity and unemployment and vacancies. While this correlation is mostly negative, it is positive in countries like Spain or Australia. This fact, in contrast to the previous one, casts some doubt on the importance of technology shocks in accounting for labor market volatility, at least for countries like Spain, which exhibit the opposite sign correlation between productivity and labor market variables relative to what the model would imply.

Finally, while vacancies and unemployment tend to be equally persistent across countries, vacancies are on average $60 \%$ more volatile than unemployment. Something one would not be able to tell just by looking at U.S. data where they have roughly the same volatility. In section 5.2 we will have something more to say about why this is the case.

\section{Model}

We use an aggregate, stochastic, discrete time version of the DMP model akin to the one used in Shimer (2005). Each country is a closed economy and even though the calibration below is country-specific, in detailing the model, we abstract from country-indexing to make the notation easier to follow.

There is an underlying exogenous productivity process $\left\{p_{t}\right\}_{t=0}^{\infty}$ that evolves according to an $\operatorname{AR}(1)$ process $\log p_{t}=\rho \log p_{t-1}+\varepsilon_{t}$, where $\varepsilon \sim N\left(0, \sigma_{\varepsilon}^{2}\right)$.

The economy is populated by two types of risk-neutral, infinitely-lived agents, both in a measure one continuum: workers and firms. Workers have preferences defined over stochastic streams of income $\left\{y_{t}\right\}_{t=0}^{\infty}$ which they discount at rate $\delta \in(0,1)$. They maximize their expected lifetime utility $E_{0} \sum_{t=0}^{\infty} \delta^{t} y_{t}$.

At any point in time a worker is either matched with a firm or not. Unmatched workers are said to be unemployed and search for jobs while receiving a utility flow of $z$. Matched workers are said to be employed and while they are not allowed to search, they earn a period wage $w_{t}$. This wage rate is the outcome of a generalized Nash bargaining problem where firms and workers bargain over the match surplus. We let the worker's bargaining power be denoted by $\beta \in(0,1)$. Firms and workers get separated with probability $s$. Firms are free to enter the market but have to pay a vacancy posting cost of $c$ to be able to obtain a match. 
Let $v_{t}$ denote the measure of vacancies posted, and $n_{t}$ denote the measure of employed people. Then, $u_{t}=1-n_{t}$ denotes the unemployment rate. The vacancy-to-unemployment ratio, $\theta_{t}=\frac{v_{t}}{u_{t}}$, or market tightness, will turn out to be a key variable in the model, as it fully describes the state of the economy. We assume the flow of new matches is given by a Cobb-Douglas function $m_{t}=A u_{t}^{\alpha} v_{t}^{1-\alpha}$. The rate at which workers find a new job is:

$$
f_{t}=\frac{m_{t}}{u_{t}}=A\left(\frac{v_{t}}{u_{t}}\right)^{1-\alpha}=A \theta^{1-\alpha},
$$

while the rate at which firms fill vacancies is

$$
q_{t}=\frac{m_{t}}{v_{t}}=A\left(\frac{u_{t}}{v_{t}}\right)^{\alpha}=A(1 / \theta)^{\alpha}=\frac{f_{t}}{\theta_{t}}
$$

Employment evolves according to $n_{t+1}=(1-s) n_{t}+m\left(u_{t}, v_{t}\right)$, while unemployment's law of motion is $u_{t+1}=u_{t}+s\left(1-u_{t}\right)-f_{t} u_{t}$. In this model, there exists a unique equilibrium in which the vacancy-to-unemployment ratio, and consequently all other variables, depends exclusively on $p$ and not on $u$, as shown in Mortensen and Nagypál (2007). This is the equilibrium we focus on.

The value of a filled position for a firm is given by:

$$
J\left(p_{t}\right)=p_{t}-w\left(p_{t}\right)+\delta E_{t}\left\{(1-s) J\left(p_{t+1}\right)+s V\left(p_{t+1} t\right)\right\}
$$

where the value of an unfilled vacancy for the firm is given by:

$$
V\left(p_{t}\right)=-c+\delta E_{t}\left\{q\left(p_{t}\right) J\left(p_{t+1}\right)+\left(1-q\left(p_{t}\right)\right) V\left(p_{t+1}\right)\right\}
$$

The value of a job for a worker is:

$$
W\left(p_{t}\right)=w\left(p_{t}\right)+\delta E_{t}\left\{s U\left(p_{t}\right)+(1-s) W\left(p_{t+1}\right)\right\}
$$

where the value of being unemployed is:

$$
U\left(p_{t}\right)=z+\delta E_{t}\left\{f\left(p_{t}\right) W\left(p_{t+1}\right)+\left(1-f\left(p_{t}\right)\right) U\left(p_{t+1}\right)\right\}
$$

The firms' free entry condition implies that, in equilibrium, entry will occur until the value of a vacancy is driven all the way down to zero: $V\left(p_{t}\right)=0$ for all $p_{t}$. This means the match surplus is given by $S\left(p_{t}\right)=W\left(p_{t}\right)+J\left(p_{t}\right)-U\left(p_{t}\right)$. Given the Nash bargaining weights, this means the firm gets $J\left(p_{t}\right)=(1-\beta) S\left(p_{t}\right)$, and the worker gets $W\left(p_{t}\right)-U\left(p_{t}\right)=\beta S\left(p_{t}\right)$. Noting that the free entry condition implies $c=\delta q_{t}\left(p_{t}\right) E_{t} J\left(p_{t+1}\right)$, this means that $w\left(p_{t}\right)=\beta p_{t}+(1-\beta) z+\beta c \theta\left(p_{t}\right)$. Finally, 
replacing this and the free entry condition into the value of a filled position for a firm yields a first-order difference equation that can be used to compute the equilibrium:

$$
\frac{c}{\delta q\left(p_{t}\right)}=E_{t}\left[(1-\delta)\left(p_{t+1}-z\right)-\beta c \theta\left(p_{t+1}\right)+(1-s) \frac{c}{q\left(p_{t+1}\right)}\right]
$$

\section{Calibration}

As we discuss in section 1, the model's ability to replicate the data will ultimately depend on modeling extensions and on the calibration details. Our choice in section 3 was to use the standard formulation of the model, and here we will also opt for the standard calibration procedure. ${ }^{6}$ We do this to establish a benchmark for each country against which to test potential solutions to the puzzle.

While most of the parameters are country specific, some are common across countries. In particular, we choose a model period to be a week and we set $\delta$, the discount rate, such as to generate a yearly interest rate of of $4 \%$. The standard calibration uses the Hosios condition, which in the context of our model means $\alpha=\beta$. Although there are a wealth of studies estimating matching functions across different countries, not all the countries in our sample, as far as we could find, were the subject of such studies, and more importantly, different studies often use different underlying data, estimation methods, etc., making it hard to compare across countries. ${ }^{7}$ As result we set $\alpha=\beta=0.72$ for all countries. This is the value used in Shimer (2005).

The remaining parameters are set on a country-by-country basis. The data on replacement rates, $z_{i}$, are from the OECD and capture the average total benefit payable in a year of unemployment in 2009. ${ }^{8}$ Even though the OECD measures compute net (not gross) replacement rates and try to take into account housing and child support related benefits, comparisons across countries may not be warranted for the reasons laid out in Whiteford (1995). Again, recall that the goal of the exercise is not a cross-country comparison, but a comparison country-by-country between data and simulated data.

The separation and job-finding rates, $s_{i}$ and $f_{i}$, are from Hobijn and Şahin (2009) who use data on job-tenure and unemployment duration to obtain their estimates. ${ }^{9}$ Table 4 shows the replacement rates and the monthly job-finding and separation rates.

Since the level of the vacancy-to-unemployment ratio is meaningless in this calibration of the

\footnotetext{
${ }^{6}$ By this we mean the one employed by Shimer (2005).

${ }^{7} \mathrm{~A}$ very nice survey of where this literature stood at the start of the decade can be found in Petrongolo and Pissarides (2001).

${ }^{8}$ Please see the appendix for further details.

${ }^{9}$ Since the estimate for the U.S. separation rate in Hobijn and Şahin (2009) is considerably below others in the literature, we use the estimates from Hagedorn and Manovskii (2008) for the U.S.'s separation and job-finding rates.
} 
model, we normalize its steady-state value to to one, which means setting $A_{i}=f_{i}$. Normalizing the steady-state value of productivity $\bar{p}_{i}=1$, we can recover the vacancy posting cost, $c_{i}$, from the analogue of (1) in steady-state.

Finally, the parameters governing productivity's law of motion, $\rho_{i}$ and $\sigma_{\varepsilon_{i}}$, are set such that the autocorrelation and the standard deviation of $\mathrm{H}-\mathrm{P}$ filtered productivity in the model and the data is the same for each country. The model does not account for movements in and out of the labor force, as it assumes the labor force to be constant. Therefore, our variables should be adjusted by the labor force. When we do that, the statistics we obtain do not change much, probably because most labor force movements are filtered out. As a result, all the statistics presented in tables 5 to 17 are unadjusted for the labor force.

\section{Results: cross-country performance}

The model's strengths and weaknesses in being able to replicate cross-country data are very similar to those regarding its ability to replicate U.S. data. It does a good job of matching the persistence in unemployment, as shown in figure 4, but it systematically underpredicts the persistence in vacancies (figure 5). This well known shortcoming can be addressed by considering extensions to the model that add mechanisms that slow the adjustment in vacancies, like in Fujita and Ramey (2007).

The model also systematically overpredicts the (absolute) correlation between productivity and labor market variables, as figure 6 shows for unemployment. ${ }^{10}$ Finally, another dimension along which the model does a good job is at capturing the correlation between unemployment and vacancies, the unconditional average slope of the Beveridge curve, as shown in figure 7.

The DMP model's transmission mechanism is such that when there is a positive productivity shock vacancies should go up (as the value of an unfilled position increases since the expected match surplus also increases), wages should go up (as workers capture part of a match surplus that has increased) and unemployment should go down. While most of the data conforms to these correlation signs, there are some exceptions. In Australia and Poland, the correlation between productivity and unemployment is positive. In Spain both the correlation between productivity and unemployment and between productivity and vacancies have signs that are the opposite of what one would expect. This either means that shocks other than neutral productivity shocks are the main driver or that unmodelled frictions, like different labor market institutions, are of paramount importance in these countries. Justiniano and Michelacci (2011) take the former perspective in the context of an RBC model with search and matching frictions and allow for multiple shocks (neutral technology shocks, investment-specific shocks, discount factor shocks, search and matching

\footnotetext{
${ }^{10}$ The figure for vacancies is even more stark as the model basically predicts a 0.99 correlation for all countries.
} 
technology shocks, job destruction shocks, and aggregate demand shocks) in 6 of these countries. They conclude that there is a lot of cross-country heterogeneity regarding the drivers of labor market-variables' fluctuations.

\subsection{Cross-country lack of amplification}

For all countries without exception, the model is unable replicate the volatility in labor market variables by an order of magnitude. This extends the finding of Shimer (2005) from the U.S. to a broad set of OECD countries. Tables 5 to 17 present the details for each country. While in the data the standard deviation of labor market tightness is higher than the standard deviation of productivity by a factor that averages 22.3 , in the model the same factor averages 1.1. Similar results hold for the volatilities of unemployment and vacancies separately.

In addition to this result, the cross-section of moments we obtain from the model and the data lends itself to tests of the model's performance in dimensions other than the aforementioned puzzle. One simple way to conduct such tests is to perform the same cross section regressions on model and data steady-states.

We illustrate this approach with an example that aims at restating the volatility puzzle puzzle through a cross-section lens: regress the standard deviation of unemployment in the model, std $(u)^{m}$, a vector of the size of our country sample, on all the exogenous variables $X$ (standard deviation of productivity, auto-correlation of productivity, job finding rates, separation rates, and replacement rates).

$$
\operatorname{std}(u)^{m}=\alpha+\beta^{m} X^{m}+\varepsilon^{m} .
$$

The $95 \%$ confidence interval for the coefficient on the standard deviation of productivity is $[0,0.3]$ and centered at 0.15 . When we run the same regression in the data, where $X^{d}$ is just $X^{m}$ augmented with GDP levels:

$$
\operatorname{std}(u)^{d}=\alpha+\beta^{d} X^{d}+\varepsilon^{d},
$$

we get that the corresponding interval is $[2.2,10.3]$, centered at 6.3 (significative at the $1 \%$ level). We are mindful of all the pitfalls that come with running cross-country regressions of this type without any other control variables (like the average unemployment rate and other institutional indicators for the labor market) or instruments. ${ }^{11}$ We do this here only to illustrate how the crosssection of data can be used to uncover dimensions in which the model may be at odds (or not) with the data.

\footnotetext{
${ }^{11}$ We also ran an analogous experiment for the volatility of vacancies with similar results.
} 


\subsection{Targeting the cyclicality of wages}

Another way the cross-sectional data can be of use is in helping evaluate the relative plausibility of the different resolutions for the volatility puzzle that have been suggested in the literature. Here we start by subjecting one of the most prominent proposals, the one in Hagedorn and Manovskii (2008), to this cross-country scrutiny.

Hagedorn and Manovskii (2008) think of the standard DMP model as an approximation to a more complex model economy with heterogeneous agents and curvature both in utility and in production. They suggest an alternative mapping between the data and a slightly modified version of the model above. Here we follow their work closely, and change the matching function to

$$
m\left(u_{t}, v_{t}\right)=\frac{u_{t} v_{t}}{\left(u_{t}^{l}+v_{t}^{l}\right)^{1 / l}}
$$

in order to have job-filling rates and vacancy filling rates that lie between zero and one.

In addition, the vacancy posting cost is no longer constant and is the sum of a capital cost component and and a labor cost component that are both cyclical:

$$
c_{p}=c_{k} p+c_{w} p^{\varepsilon_{w, p}}
$$

where $\varepsilon_{w, p}$ is the elasticity of wages with respect to productivity, and $c_{k}$ and $c_{w}$ are endogenous objects that depend on the steady-state values of unemployment, vacancies, production, job filling rates and income factor shares. ${ }^{12}$

Regarding the mapping between data and model, while separation rates continue to be calibrated directly to their data counterpart, the same is not true of replacement rates. The idea being that the utility flow unemployed agents receive in the model, $z$, stands in for more than measured replacement rates and include things like home production and leisure. The strategy is then to set values for parameters $\beta_{i}, z_{i}$, and $l_{i}$ for each country, so as to match the average job finding rate, $f_{i}$, the average labor market tightness, $\theta_{i}$, and the elasticity of wages with respect to productivity that we obtain from the data, $\varepsilon_{w, p}^{i}$.

The values for the average job-finding rate in each country, $f_{i}$ appear in table 4 . To compute the average market tightness we use the fact that $\theta_{i}=f_{i} / q_{i}$. We don't have country specific data for the vacancy-filling rate $q_{i}$, so we use the value reported by den Haan, Ramey, and Watson (2000), $q_{i}=q=0.71$ for all countries. ${ }^{13}$ To compute the labor share of income we use OECD data. For each country and quarter we take employee compensation and subtract indirect taxes and then

\footnotetext{
${ }^{12}$ For the exact form of $c_{k}$ and $c_{w}$, please see Hagedorn and Manovskii (2008).

${ }^{13}$ van Ours and Ridder (1992) also find a similar value for the Netherlands.
} 
divide this by GDP minus indirect taxes. ${ }^{14}$ We then multiply this share by labor productivity; this gives us total wages per worker. We H-P filter this series and compute its elasticity with respect to productivity. The results appear in figure 3 for all the countries in our sample for which data was available. The measure varies substantially across countries, from near acyclicality in Austria to a relatively strong procyclicality in Spain.

The calibration is able to match all targets and the business-cycle statistics are shown from tables 18 to 26 . While the model, under this calibration strategy, is more than able to account for the volatility of labor market variables in most countries, it is unable to do so for others, notably Portugal and Spain. In what follows we use these results to investigate exactly how robust this calibration strategy is in addressing the volatility puzzle.

To do this we start by generating a series of simulated economies that differ only in their average job finding rates, $f$, and in their unconditional first-order auto-correlation of the productivity process. ${ }^{15}$ Other this, the parameters are calibrated to common targets (eg. separation rate, wage elasticity). Countries like Portugal and Spain exhibit both very limited persistence in their labor productivity processes as well as very low job finding rates, when compared to countries like the U.S..

The first column of figure 8 reports the resulting volatility in labor market variables for each of these economies. The top panel shows that while an economy with a job finding rate of $3.5 \%$ (Portugal is at $3.9 \%$ ) and a first order auto-correlation of 0.5 (Portugal is at 0.46 ) generates a standard deviation of unemployment of 0.0037 , an economy with the U.S. job finding rate, $48 \%$, and first order auto-correlation, 0.75, generates a standard deviation of unemployment of 0.0748. Therefore these two factors together can account for a factor of 20 in the standard deviation of unemployment.

The second panel in the first column shows that as far as the volatility of vacancies goes, the persistence of the productivity process can account for roughly a factor of 6 , while variations in the job finding rate actually work the other way: economies with lower job finding rates actually exhibit higher volatility in vacancies, although not by a large factor.

We need to answer two questions. The first is why do economies that exhibit more persistence in their productivity processes generate a larger volatility in labor market variables? The answer is that given a positive productivity shock, the incentive for firms to post vacancies is stronger the more persistent the productivity process is, as expected profits from doing so are larger, and therefore the response of vacancies will be stronger. Given the same job finding rates and separation

\footnotetext{
${ }^{14} \mathrm{~A}$ better measure would subtract other ambiguous components of income. Unfortunately the OECD does not report proprietors' income separately from corporate profits, so that our measure apportions the totality of proprietors' income to capital income.

${ }^{15}$ We vary both $\rho$ and $\sigma_{\varepsilon}$ to generate different autocorrelations while keeping the unconditional variance constant.
} 
rates, unemployment will then decrease faster. The second question is why do are economies with higher job finding rates exhibit higher volatility in unemployment but not in vacancies? The answer here is that conditional on a positive productivity shock and on a given number of posted vacancies, unemployment will decrease by less the smaller the job finding rate is. On the other hand, because this reduces expected profits for firms, more vacancies will be posted when the job finding rate is smaller, conditional on everything else.

Points to be developed: the overprediction for Japan; the $\mathrm{u}-\mathrm{v}$ poor performance.

While the HM calibration is successful (with the caveats noted above) in bringing the model closer to the data along the labor market volatility dimension, it fails to do so along other dimensions. Figures 11-14, are the analogues of figures 4-7 under the HM calibration. Its performance in terms of the persistence of labor market variables and the correlation of unemployment and vacancies is worse than the standard model's, while it does marginally better regarding the correlation of productivity with unemployment and vacancies (figure not shown).

\section{Conclusion}

Cross-country data can be used as a tool to better understand the dimensions along which search and matching models can successfully approximate relevant business-cycle moments. We start by establishing that the model's inability to deliver the sort of volatility in labor market variables present in the data extends beyond the U.S. and to a large set of OECD countries. We go on to show that the model, at least with technology shocks as the main driver, has no hope of capturing the mechanics of labor markets in some countries where the correlations implied by the model's transmission mechanism are contradicted by the data.

To further illustrate how useful this cross-country scrutiny can be, we modify the standard model as proposed by Hagedorn and Manovskii (2008) and show that while the model's ability to match the labor market variables' volatility observed in the data improves substantially, this improvement in not ubiquitous. In particular it does not work for economies that have sufficiently small job-finding rates and/or productivity processes that are not persistent enough. Moreover, this modification fails to improve the model's cross-country performance along other margins.

Our findings cast some doubt on the DMP model's usefulness to serve as the workhorse of labor market research at business-cycle frequencies for two reasons. The first one is that some countries exhibit sets of moments that are in plain disagreement with the model's basic mechanisms; the second one is that extensions of the basic model seem to work for some countries, but not others, while not improving matters along other margins (which, granted, they were not designed to do so). These findings lead one to think that looking for shocks (other than productivity) that may 
be impinging on the labor market, as in Justiniano and Michelacci (2011) may be a promising line of research.

Nonetheless, the Hagedorn and Manovskii (2008) framework is one of many that have been proposed in the literature to try to reconcile the predictions of the DMP model with the data. In future work we plan to look at others, like rigid wages as in Shimer (2004), Hall (2005), or Kennan (2010), labor turnover costs, as in Silva and Toledo (2009), on-the-job search, as in Nagypál (2006) Krause and Lubik (2006), or Tasci (2007), and financial frictions, as in Petrosky-Nadeau and Wasmer (2010). 


\section{References}

Blanchard, O. (2006): "European Unemployment: The Evolution of Facts and Ideas," Economic Policy, 21, 5-59.

Blanchard, O., and J. Wolfers (2000): "The Role of Shocks and Institutions in the Rise of European Unemployment: The Aggregate Evidence," Economic Journal, 110, 1-33.

Costain, J., and M. Reiter (2008): "Business Cycles, Unemployment Insurance, and the Calibration of Matching Models," Journal of Economic Dynamics and Control, 32(4), 1120-55.

Den HaAn, W., G. Ramey, and J. Watson (2000): "Job Destruction and Propagation of Shocks," American Economic Review, 90(3), 482-98.

Diamond, P. (1982): “Aggregate Demand Management in Search Equilibrium," Journal of Political Economy, 90(5), 881-894.

Elsby, M. W., B. Hobijn, and A. Sahin (2011): "Unemployment Dynamics in the OECD," Tinbergen Institute Discussion Papers 11-159/3, Tinbergen Institute.

Esteban-Pretel, J., N. Ryo, and T. Ryuichi (2011): “Japan's Labor Market Cyclicality and the Volatility Puzzle," Discussion papers 11040, Research Institute of Economy, Trade and Industry (RIETI).

Fujita, S., And G. RAmey (2007): "Job matching and propagation," Journal of Economic Dynamics and Control, 31(11), 3671 - 3698.

Hagedorn, M., And Y. Manovski (2008): "The Cyclical Behavior of Cyclical Unemployment and Vacancies Revisited," American Economic Review, 98(4), 1692-1706.

HALl, R. (2005): "Employment Fluctuations with Equilibrium Wage Stickiness," American Economic Review, 95(1), 50-65.

HobiJn, B., And A. ŞAhIn (2009): "Job-finding and Separattion Rates in the OECD," Economics Letters, 104, 107-111.

Hornstein, A., P. Krusell, and G. L. Violante (2005): "Unemployment and Vacancy Fluctuations in the Matching Model: Inspecting the Mechanism," Federal Reserve Bank of Richmond Economic Quarterly, 91(3), 19-50. 
Justiniano, A., And C. Michelacci (2011): "The Cyclical Behavior of Equilibrium Unemployment and Vacancies in the US and Europe," NBER Working Papers 17429, National Bureau of Economic Research.

Kennan, J. (2010): "Private Information, Wage Bargaining and Employment Fluctuations," Review of Economic Studies, 77(2), 633-664.

Krause, M., And T. Lubik (2006): "The Cyclical Upgrading of Labor and On-the-Job Search," Labour Economics, 13(4), 459-77.

Miяamoto, H. (2011): "Cyclical Behavior of Unemployment and Job Vacancies in Japan," Japan and the World Economy, 23, 214-25.

Mortensen, D., and E. Nagypál (2007): "More on Unemployment and Vacancy Fluctuations," Review of Economic Dynamics, 10(3), 327-47.

Mortensen, D., and C. Pissarides (1994): "Job Creation and Job Destruction in the Theory of Unemployment," Review of Economic Studies, 61(3), 397-415.

NagypáL, E. (2006): "Amplification of Productivity Shocks: Why Dont Vacancies Like to Hire the Unemployed?," in Structural Models of Wage and Employment Dynamics, vol. 275 of "Contributions to Economic Analysis", ed. by H. Bunzel, B. J. Christensen, G. R. Neumann, and J.-M. Robin, pp. 481-506. Elsevier, Amsterdam.

Nickell, S. (1997): "Unemployment and Labor Market Rigidities: Europe versus North America," Journal of Economic Perspectives, 11(3), 55-74.

Nickell, S., L. Nunziata, and W. Ochel (2005): "Unemployment in the OECD Since the 1960s. What Do We Know?," Economic Journal, 115, 1-27.

Petrongolo, B., And C. A. Pissarides (2001): "Looking into the Black Box: A Survey of the Matching Function," Journal of Economic Literature, 39(2), 390-431.

Petrosky-Nadeau, N., and E. Wasmer (2010): "The Cyclical Volatility of Labor Markets under Frictional Financial Markets," GSIA Working Paper, 2010-E1.

Pissarides, C. (2000): Equilibrium Unemployment Theory. MIT Press.

(2009): “The Unemployment Volatility Puzzle: Is Wage Stickiness the Answer?," Econometrica, 77(5), 1339-69. 
Shimer, R. (2004): "The Consequences of Rigid Wages in Search Models," Journal of the European Economic Association (Papers and Proceedings), 2, 469-79.

- (2005): "The Cyclical Behavior of Equilibrium Unemployment and Vacancies," American Economic Review, 95(1), 25-49.

Silva, J., And M. Toledo (2009): "Labor Turnover Costs and the Cyclical Behavior of Vacancies and Unemployment," Macroeconomic Dynamics, 13(1), 76-96.

Tasci, M. (2007): "On-the-Job Search and Labor Market Reallocation," Federal Reserve Bank of Cleveland Working Paper, 07-25.

VAn Ours, J., And G. Ridder (1992): "Vacancies and the Recruitment of New Employees," Journal of Labor Economics, 10(2), 138-55.

Whiteford, P. (1995): "The Use of Replacement Rates in International Comparisons of Benefit Systems," Discussion Papers 0054, University of New South Wales, Social Policy Research Centre.

ZhANG, M. (2008): "Cyclical Behavior of Unemployment and Job Vacancies: A Comparison between Canada and the United States," The B.E. Journal of Macroeconomics, 8(1), 27. 
Figure 1: Productivity and unemployment

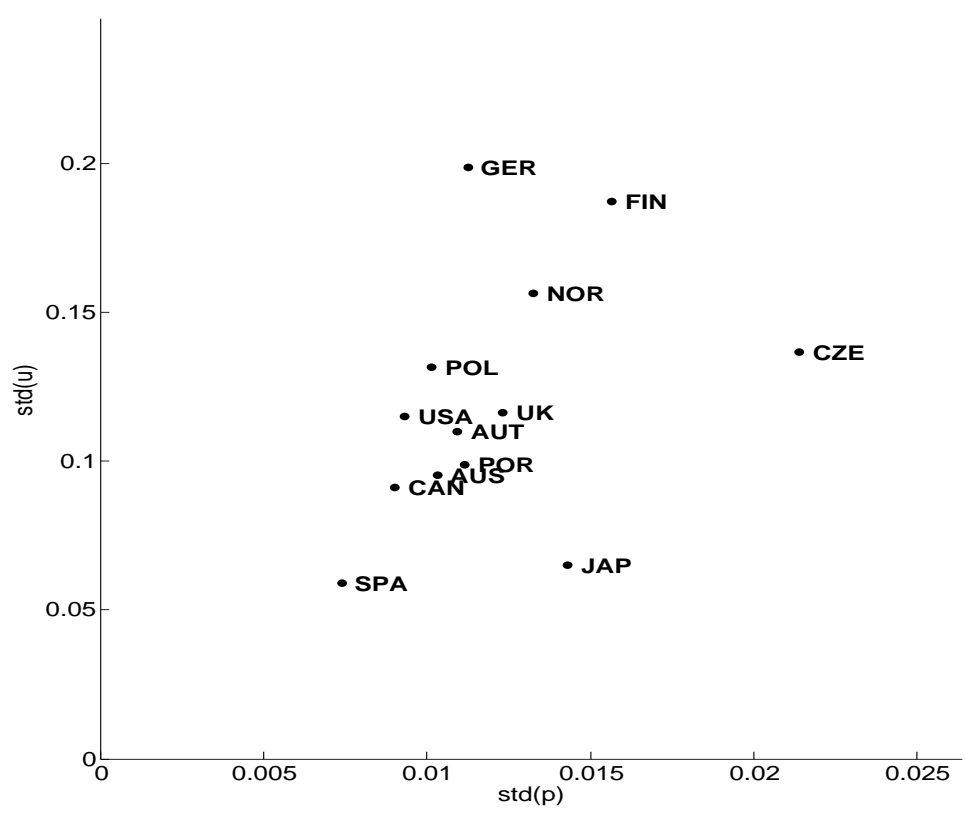

Figure 2: Productivity and vacancies

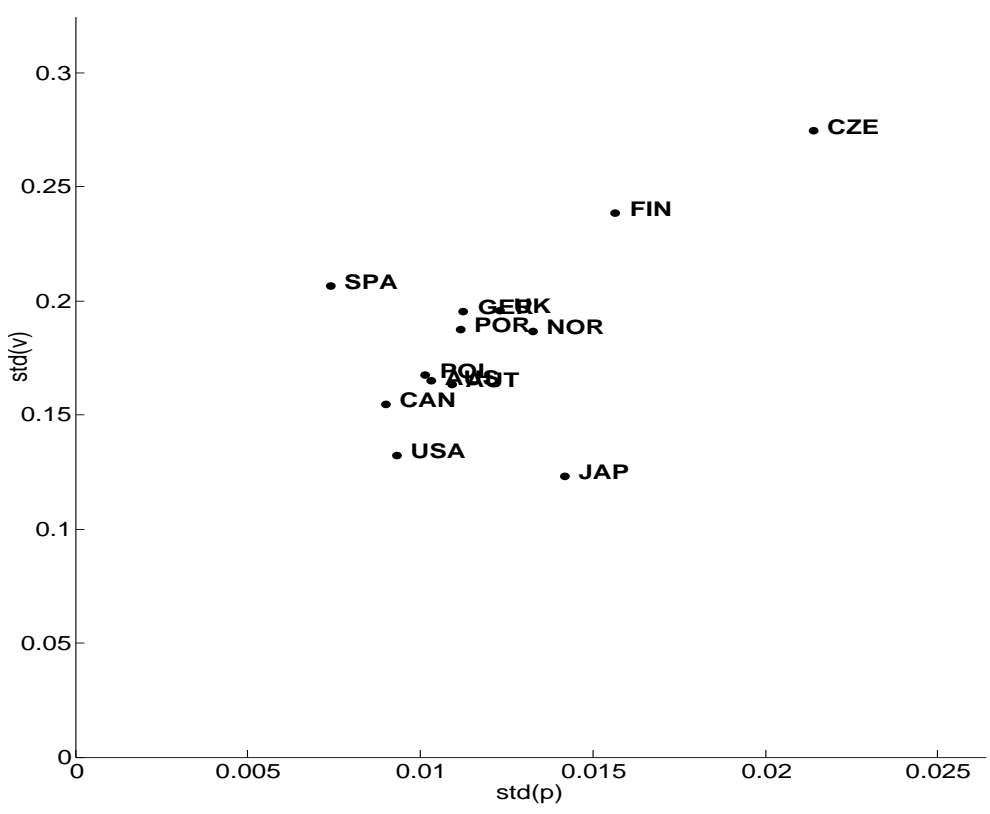




\section{Table 1: Vacancies}

\begin{tabular}{lcccc}
\hline Countries & Start date & End date & Std. dev. & Autocorr. \\
\hline Australia & Q2-1979 & Q3-2011 & 0.1642 & 0.8689 \\
Austria & Q1-1955 & Q3-2011 & 0.1577 & 0.9251 \\
Canada & Q1-1962 & Q3-2011 & 0.1545 & 0.9155 \\
Czech Rep. & Q1-1991 & Q2-2011 & 0.2649 & 0.9132 \\
Finland & Q1-1961 & Q2-2010 & 0.2385 & 0.8948 \\
Germany & Q1-1962 & Q2-2010 & 0.1954 & 0.9387 \\
Japan & Q2-1967 & Q4-2011 & 0.1254 & 0.9303 \\
Norway & Q1-1955 & Q3-2011 & 0.1874 & 0.8803 \\
Poland & Q1-1990 & Q2-2011 & 0.1824 & 0.8524 \\
Portugal & Q1-1974 & Q3-2011 & 0.2588 & 0.8927 \\
Spain & Q1-1977 & Q1-2005 & 0.2065 & 0.8031 \\
U.K. & Q3-1958 & Q3-2011 & 0.1991 & 0.9205 \\
U.S. & Q1-1955 & Q3-2011 & 0.1353 & 0.9036 \\
\hline
\end{tabular}

Table 2: Unemployment

\begin{tabular}{lcccc}
\hline Countries & Start date & End date & Std. dev. & Autocorr. \\
\hline Australia & Q1-1964 & Q2-2011 & 0.1100 & 0.8424 \\
Austria & Q1-1969 & Q2-2011 & 0.1098 & 0.6433 \\
Canada & Q1-1955 & Q3-2011 & 0.1069 & 0.8785 \\
Czech Rep. & Q1-1990 & Q2-2011 & 0.2535 & 0.6704 \\
Finland & Q1-1958 & Q4-2010 & 0.1872 & 0.8856 \\
Germany & Q1-1956 & Q2-2011 & 0.1985 & 0.9188 \\
Japan & Q1-1955 & Q2-2011 & 0.0699 & 0.7993 \\
Norway & Q1-1972 & Q2-2011 & 0.1564 & 0.7573 \\
Poland & Q4-1991 & Q2-2011 & 0.1223 & 0.9352 \\
Portugal & Q1-1983 & Q2-2011 & 0.0994 & 0.9155 \\
Spain & Q1-1977 & Q2-2011 & 0.0842 & 0.9405 \\
U.K. & Q1-1971 & Q2-2011 & 0.1163 & 0.9320 \\
U.S. & Q1-1955 & Q3-2011 & 0.1177 & 0.8994 \\
\hline
\end{tabular}


Table 3: Productivity

\begin{tabular}{lcccc}
\hline Countries & Start date & End date & Std. dev. & Autocorr. \\
\hline Australia & Q1-1964 & Q2-2011 & 0.0118 & 0.5541 \\
Austria & Q1-1960 & Q2-2011 & 0.0104 & 0.6239 \\
Canada & Q1-1960 & Q2-2011 & 0.0090 & 0.7111 \\
Czech Rep. & Q1-1994 & Q2-2011 & 0.0214 & 0.7282 \\
Finland & Q1-1960 & Q2-2011 & 0.0159 & 0.6774 \\
Germany & Q1-1960 & Q2-2011 & 0.0112 & 0.5918 \\
Japan & Q1-1960 & Q2-2011 & 0.0143 & 0.7385 \\
Norway & Q1-1960 & Q2-2011 & 0.0124 & 0.5472 \\
Poland & Q1-1995 & Q2-2011 & 0.0102 & 0.4515 \\
Portugal & Q2-1983 & Q2-2011 & 0.0112 & 0.4684 \\
Spain & Q3-1972 & Q2-2011 & 0.0078 & 0.6428 \\
U.K. & Q1-1960 & Q2-2011 & 0.0119 & 0.7322 \\
U.S. & Q1-1960 & Q2-2011 & 0.0093 & 0.7544 \\
\hline
\end{tabular}

Table 4: Country-specific parameters

\begin{tabular}{lccc}
\hline Countries & Replacement & Separation & Job-Finding \\
\hline Australia & 0.5353 & 0.0175 & 0.1705 \\
Austria & 0.6182 & 0.0106 & 0.1561 \\
Canada & 0.5535 & 0.0178 & 0.2890 \\
Czech Rep. & 0.5535 & 0.0094 & 0.0806 \\
Finland & 0.6984 & 0.0138 & 0.1336 \\
Germany & 0.6375 & 0.0106 & 0.0698 \\
Japan & 0.7459 & 0.0060 & 0.1907 \\
Norway & 0.7068 & 0.0134 & 0.3053 \\
Poland & 0.4617 & 0.0099 & 0.0720 \\
Portugal & 0.6042 & 0.0096 & 0.0388 \\
Spain & 0.4726 & 0.0203 & 0.0398 \\
U.K. & 0.6142 & 0.0153 & 0.1127 \\
U.S. & 0.3346 & 0.0260 & 0.4772 \\
\hline
\end{tabular}


Table 5: Australia

\begin{tabular}{|c|c|c|c|c|c|c|c|c|c|}
\hline & \multicolumn{4}{|c|}{ Data } & \multicolumn{4}{|c|}{ Model } \\
\hline & & $\mathrm{u}$ & $\mathrm{v}$ & $\mathrm{v} / \mathrm{u}$ & $\mathrm{p}$ & $\mathrm{u}$ & $\mathrm{v}$ & $\mathrm{v} / \mathrm{u}$ & $\mathrm{p}$ \\
\hline \multirow{2}{*}{\multicolumn{2}{|c|}{$\begin{array}{l}\text { Std. Dev. } \\
\text { Autocorr. }\end{array}$}} & 0.095 & 0.165 & 0.240 & 0.010 & 0.003 & 0.015 & 0.017 & 0.010 \\
\hline & & 0.907 & 0.869 & 0.903 & 0.719 & 0.879 & 0.664 & 0.719 & 0.719 \\
\hline \multirow{4}{*}{ Correlation } & $\mathrm{u}$ & 1 & -0.681 & -0.864 & 0.056 & 1 & -0.642 & -0.747 & -0.747 \\
\hline & $\mathrm{v}$ & - & 1 & 0.957 & 0.230 & - & 1 & 0.989 & 0.989 \\
\hline & $\mathrm{v} / \mathrm{u}$ & - & - & 1 & 0.136 & - & - & 1 & 1.000 \\
\hline & $\mathrm{p}$ & - & - & - & 1 & - & - & - & 1 \\
\hline
\end{tabular}

Dates: Q2-1979: Q2-2011

Table 6: Austria

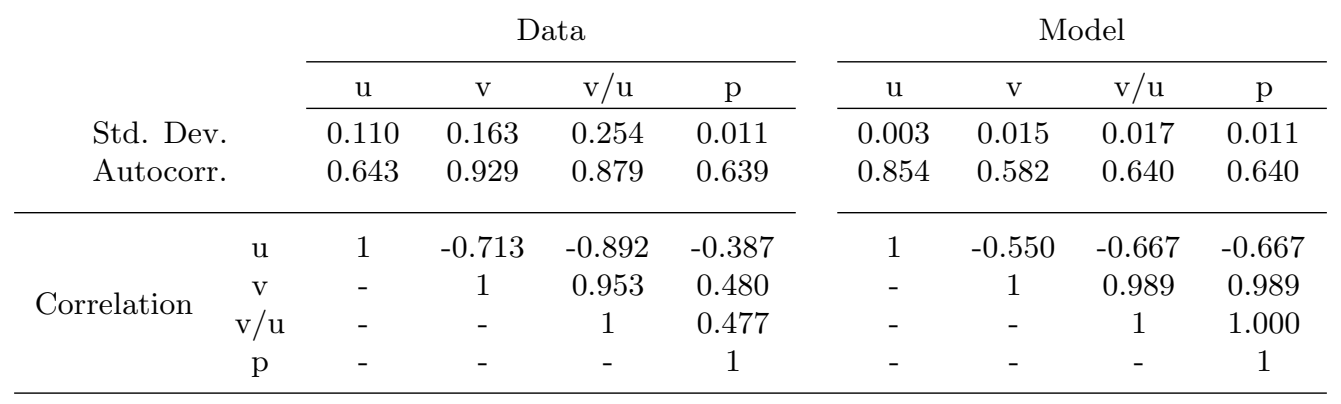

Dates: Q1-1969: Q2-2011

Table 7: Canada

\begin{tabular}{|c|c|c|c|c|c|c|c|c|c|}
\hline & \multicolumn{4}{|c|}{ Data } & \multicolumn{4}{|c|}{ Model } \\
\hline & & $\mathrm{u}$ & $\mathrm{v}$ & $\mathrm{v} / \mathrm{u}$ & $\mathrm{p}$ & $\mathrm{u}$ & $\mathrm{v}$ & $\mathrm{v} / \mathrm{u}$ & $\mathrm{p}$ \\
\hline \multirow{2}{*}{\multicolumn{2}{|c|}{$\begin{array}{l}\text { Std. Dev. } \\
\text { Autocorr. }\end{array}$}} & 0.091 & 0.155 & 0.239 & 0.009 & 0.004 & 0.014 & 0.017 & 0.009 \\
\hline & & 0.888 & 0.916 & 0.919 & 0.717 & 0.838 & 0.653 & 0.718 & 0.718 \\
\hline \multirow{4}{*}{ Correlation } & $\mathrm{u}$ & 1 & -0.876 & -0.950 & -0.247 & 1 & -0.772 & -0.856 & -0.856 \\
\hline & $\mathrm{v}$ & - & 1 & 0.983 & 0.299 & - & 1 & 0.990 & 0.989 \\
\hline & $\mathrm{v} / \mathrm{u}$ & - & - & 1 & 0.288 & - & - & 1 & 1.000 \\
\hline & $\mathrm{p}$ & - & - & - & 1 & - & - & - & 1 \\
\hline
\end{tabular}

Dates: Q1-1962: Q2-2011 
Table 8: Czech Republic

\begin{tabular}{|c|c|c|c|c|c|c|c|c|c|}
\hline & \multicolumn{4}{|c|}{ Data } & \multicolumn{4}{|c|}{ Model } \\
\hline & & $\mathrm{u}$ & $\mathrm{V}$ & $\mathrm{v} / \mathrm{u}$ & $\mathrm{p}$ & $\mathrm{u}$ & $\mathrm{v}$ & $\mathrm{v} / \mathrm{u}$ & $\mathrm{p}$ \\
\hline \multirow{2}{*}{\multicolumn{2}{|c|}{$\begin{array}{l}\text { Std. Dev. } \\
\text { Autocorr. }\end{array}$}} & 0.137 & 0.275 & 0.399 & 0.021 & 0.003 & 0.018 & 0.017 & 0.021 \\
\hline & & 0.927 & 0.927 & 0.931 & 0.728 & 0.944 & 0.684 & 0.728 & 0.727 \\
\hline \multirow{4}{*}{ Correlation } & $\mathrm{u}$ & 1 & -0.867 & -0.939 & -0.435 & 1 & -0.512 & -0.619 & -0.619 \\
\hline & $\mathrm{v}$ & - & 1 & 0.985 & 0.631 & - & 1 & 0.991 & 0.991 \\
\hline & $\mathrm{v} / \mathrm{u}$ & - & - & 1 & 0.583 & - & - & 1 & 1.000 \\
\hline & $\mathrm{p}$ & - & - & - & 1 & - & - & - & 1 \\
\hline
\end{tabular}

Dates: Q1-1994: Q2-2011

Table 9: Finland

\begin{tabular}{|c|c|c|c|c|c|c|c|c|c|}
\hline & \multicolumn{4}{|c|}{ Data } & \multicolumn{4}{|c|}{ Model } \\
\hline & & $\mathrm{u}$ & $\mathrm{v}$ & $\mathrm{v} / \mathrm{u}$ & $\mathrm{p}$ & $\mathrm{u}$ & $\mathrm{v}$ & $\mathrm{v} / \mathrm{u}$ & $\mathrm{p}$ \\
\hline \multirow{2}{*}{\multicolumn{2}{|c|}{$\begin{array}{l}\text { Std. Dev. } \\
\text { Autocorr. }\end{array}$}} & 0.187 & 0.238 & 0.407 & 0.016 & 0.005 & 0.028 & 0.031 & 0.016 \\
\hline & & 0.899 & 0.895 & 0.915 & 0.665 & 0.874 & 0.615 & 0.665 & 0.665 \\
\hline \multirow{4}{*}{ Correlation } & $\mathrm{u}$ & 1 & -0.826 & -0.944 & -0.282 & 1 & -0.532 & -0.645 & -0.645 \\
\hline & $\mathrm{v}$ & - & 1 & 0.966 & 0.408 & - & 1 & 0.990 & 0.990 \\
\hline & $\mathrm{v} / \mathrm{u}$ & - & - & 1 & 0.369 & - & - & 1 & 1.000 \\
\hline & $\mathrm{p}$ & - & - & - & 1 & - & - & - & 1 \\
\hline
\end{tabular}

Dates: Q1-1961: Q2-2010

Table 10: Germany

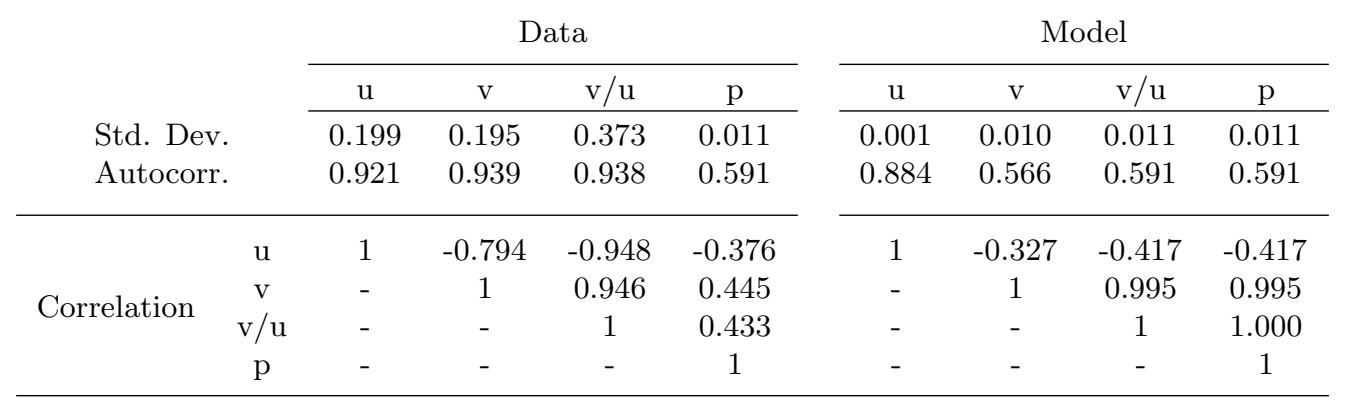

Dates: Q1-1962: Q2-2010 
Table 11: Japan

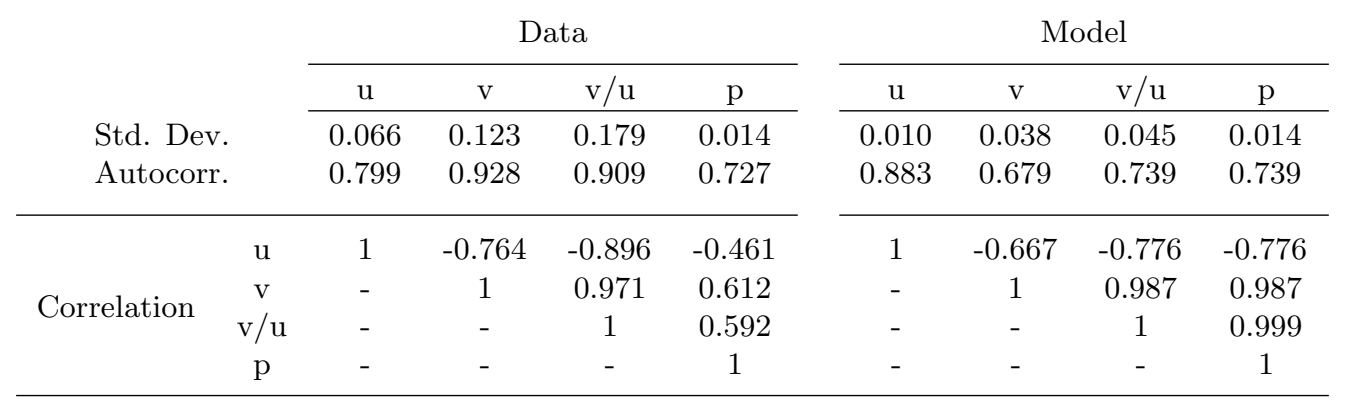

Dates: Q2-1967: Q2-2011

Table 12: Norway

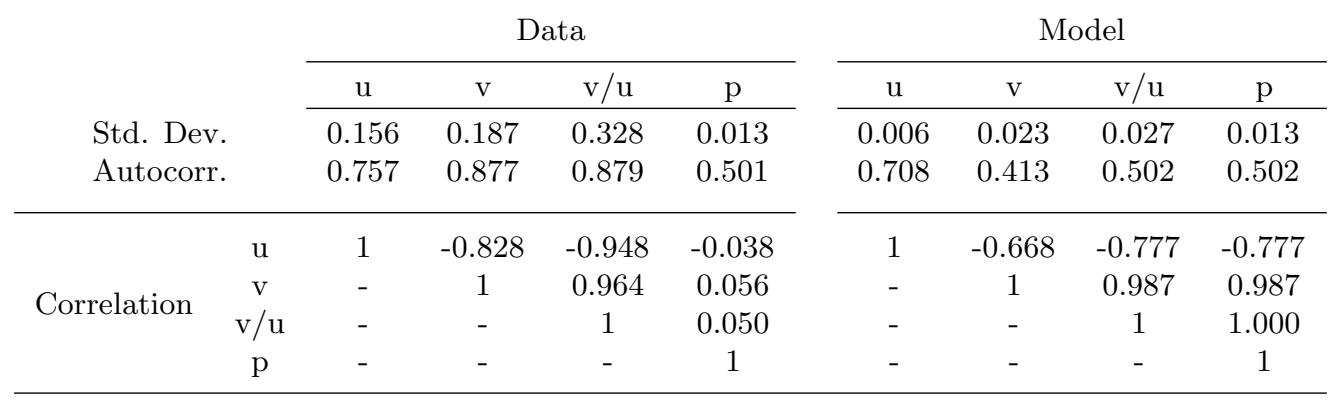

Dates: Q1-1972: Q2-2011

Table 13: Poland

\begin{tabular}{|c|c|c|c|c|c|c|c|c|c|}
\hline & \multicolumn{4}{|c|}{ Data } & \multicolumn{4}{|c|}{ Model } \\
\hline & & $\mathrm{u}$ & $\mathrm{v}$ & $\mathrm{v} / \mathrm{u}$ & $\mathrm{p}$ & $\mathrm{u}$ & $\mathrm{v}$ & $\mathrm{v} / \mathrm{u}$ & $\mathrm{p}$ \\
\hline \multirow{2}{*}{\multicolumn{2}{|c|}{$\begin{array}{l}\text { Std. Dev. } \\
\text { Autocorr. }\end{array}$}} & 0.132 & 0.168 & 0.253 & 0.010 & 0.000 & 0.004 & 0.004 & 0.010 \\
\hline & & 0.948 & 0.862 & 0.925 & 0.451 & 0.843 & 0.425 & 0.451 & 0.451 \\
\hline \multirow{4}{*}{ Correlation } & $\mathrm{u}$ & 1 & -0.416 & -0.797 & 0.244 & 1 & -0.277 & -0.362 & -0.362 \\
\hline & $\mathrm{v}$ & - & 1 & 0.881 & 0.271 & - & 1 & 0.996 & 0.996 \\
\hline & $\mathrm{v} / \mathrm{u}$ & - & - & 1 & 0.052 & - & - & 1 & 1.000 \\
\hline & $\mathrm{p}$ & - & - & - & 1 & - & - & - & 1 \\
\hline
\end{tabular}

Dates: Q1-1995: Q2-2011 
Table 14: Portugal

\begin{tabular}{|c|c|c|c|c|c|c|c|c|c|}
\hline & \multicolumn{4}{|c|}{ Data } & \multicolumn{4}{|c|}{ Model } \\
\hline & & $\mathrm{u}$ & $\mathrm{v}$ & $\mathrm{v} / \mathrm{u}$ & $\mathrm{p}$ & $\mathrm{u}$ & $\mathrm{v}$ & $\mathrm{v} / \mathrm{u}$ & $\mathrm{p}$ \\
\hline \multirow{2}{*}{\multicolumn{2}{|c|}{$\begin{array}{l}\text { Std. Dev. } \\
\text { Autocorr. }\end{array}$}} & 0.099 & 0.188 & 0.251 & 0.011 & 0.000 & 0.004 & 0.004 & 0.011 \\
\hline & & 0.915 & 0.884 & 0.908 & 0.468 & 0.872 & 0.456 & 0.467 & 0.467 \\
\hline \multirow{4}{*}{ Correlation } & $\mathrm{u}$ & 1 & -0.491 & -0.760 & -0.082 & 1 & -0.183 & -0.236 & -0.236 \\
\hline & $\mathrm{v}$ & - & 1 & 0.940 & 0.282 & - & 1 & 0.999 & 0.998 \\
\hline & $\mathrm{v} / \mathrm{u}$ & - & - & 1 & 0.243 & - & - & 1 & 1.000 \\
\hline & $\mathrm{p}$ & - & - & - & 1 & - & - & - & 1 \\
\hline
\end{tabular}

Dates: Q2-1983: Q2-2011

Table 15: Spain

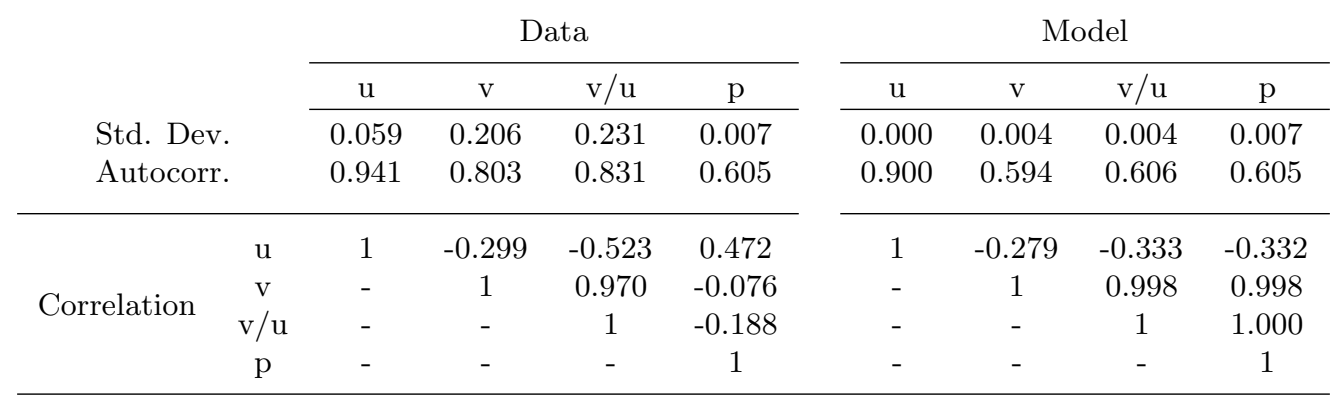

Dates: Q1-1977 : Q1-2005

Table 16: U.K.

\begin{tabular}{|c|c|c|c|c|c|c|c|c|c|}
\hline & \multicolumn{4}{|c|}{ Data } & \multicolumn{4}{|c|}{ Model } \\
\hline & & $\mathrm{u}$ & $\mathrm{v}$ & $\mathrm{v} / \mathrm{u}$ & $\mathrm{p}$ & $\mathrm{u}$ & $\mathrm{v}$ & $\mathrm{v} / \mathrm{u}$ & $\mathrm{p}$ \\
\hline \multirow{2}{*}{\multicolumn{2}{|c|}{$\begin{array}{l}\text { Std. Dev. } \\
\text { Autocorr. }\end{array}$}} & 0.116 & 0.196 & 0.293 & 0.012 & 0.005 & 0.024 & 0.027 & 0.012 \\
\hline & & 0.932 & 0.918 & 0.926 & 0.767 & 0.920 & 0.728 & 0.768 & 0.767 \\
\hline \multirow{4}{*}{ Correlation } & $\mathrm{u}$ & 1 & -0.749 & -0.897 & -0.185 & 1 & -0.577 & -0.683 & -0.683 \\
\hline & $\mathrm{v}$ & - & 1 & 0.965 & 0.625 & - & 1 & 0.991 & 0.990 \\
\hline & $\mathrm{v} / \mathrm{u}$ & - & - & 1 & 0.491 & - & - & 1 & 1.000 \\
\hline & $\mathrm{p}$ & - & - & - & 1 & - & - & - & 1 \\
\hline
\end{tabular}

Dates: Q1-1971: Q2-2011 
Table 17: U.S.

\begin{tabular}{|c|c|c|c|c|c|c|c|c|c|}
\hline & \multicolumn{4}{|c|}{ Data } & \multicolumn{4}{|c|}{ Model } \\
\hline & & $\mathrm{u}$ & $\mathrm{v}$ & $\mathrm{v} / \mathrm{u}$ & $\mathrm{p}$ & $\mathrm{u}$ & $\mathrm{v}$ & $\mathrm{v} / \mathrm{u}$ & $\mathrm{p}$ \\
\hline \multirow{2}{*}{\multicolumn{2}{|c|}{$\begin{array}{l}\text { Std. Dev. } \\
\text { Autocorr. }\end{array}$}} & 0.115 & 0.132 & 0.243 & 0.009 & 0.003 & 0.010 & 0.013 & 0.009 \\
\hline & & 0.915 & 0.913 & 0.920 & 0.754 & 0.815 & 0.707 & 0.754 & 0.754 \\
\hline \multirow{4}{*}{ Correlation } & $\mathrm{u}$ & 1 & -0.932 & -0.980 & -0.242 & 1 & -0.897 & -0.940 & -0.940 \\
\hline & $\mathrm{v}$ & - & 1 & 0.985 & 0.408 & - & 1 & 0.994 & 0.994 \\
\hline & $\mathrm{v} / \mathrm{u}$ & - & - & 1 & 0.337 & - & - & 1 & 1.000 \\
\hline & $\mathrm{p}$ & - & - & - & 1 & - & - & - & 1 \\
\hline
\end{tabular}

Dates: Q1-1960 : Q2-2011

Figure 3: Wage elasticities

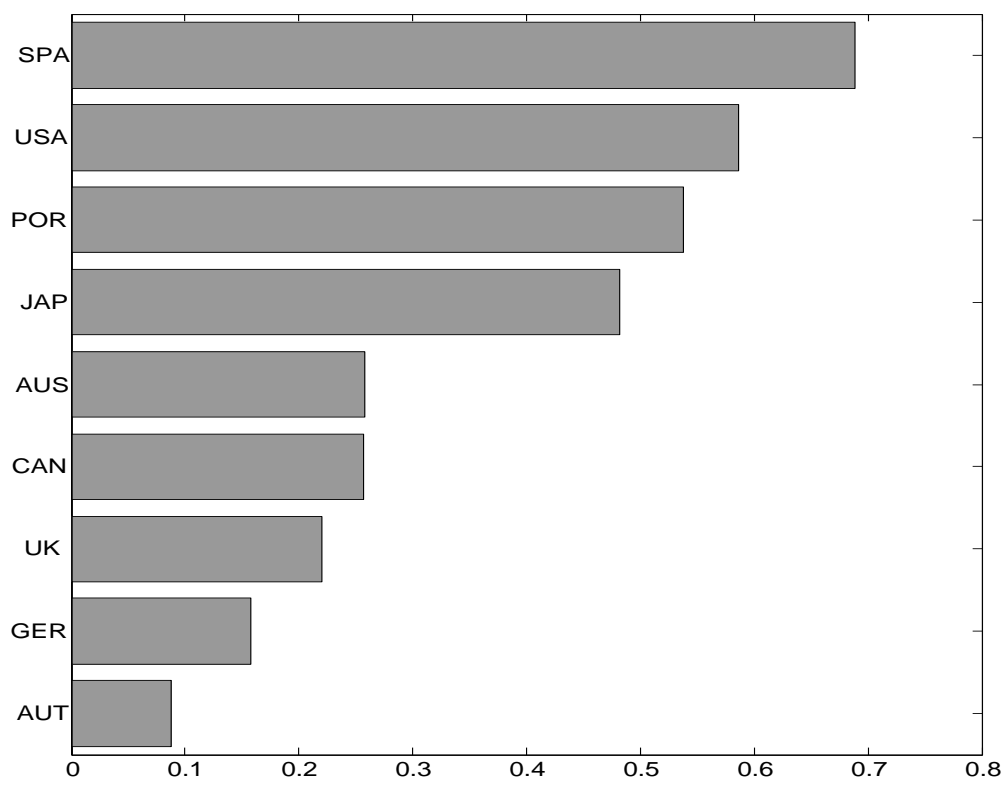


Figure 4: Unemployment autocorrelation

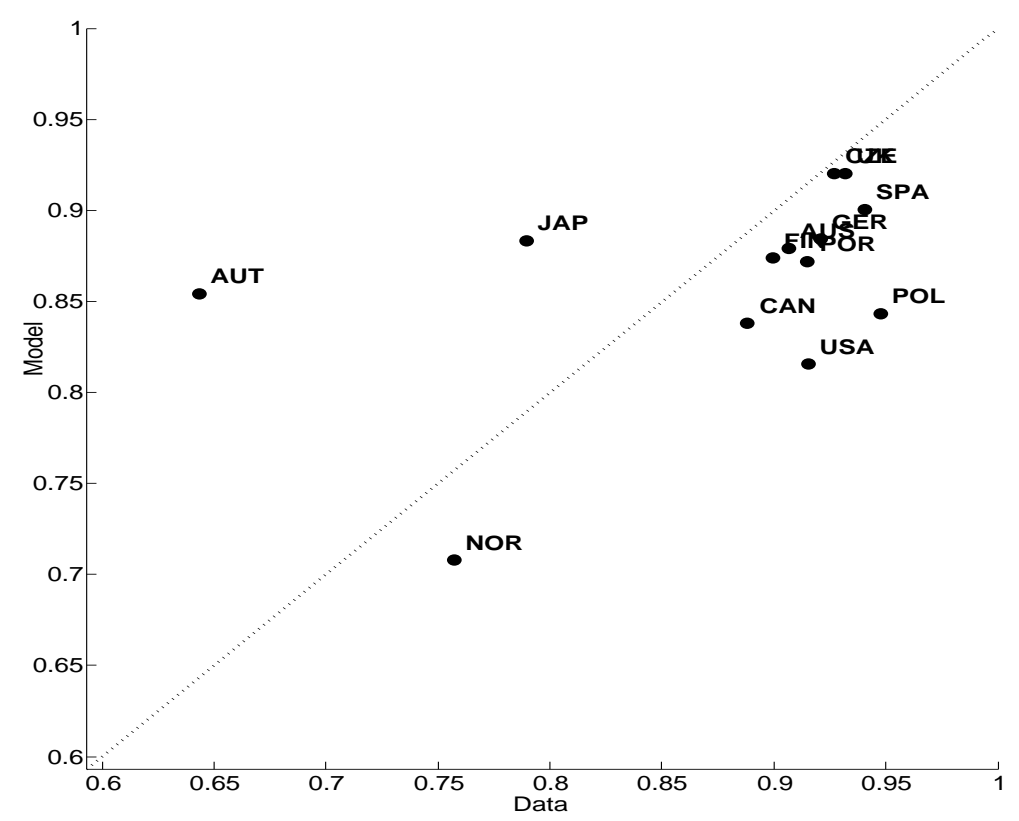

Figure 5: Vacancies autocorrelation

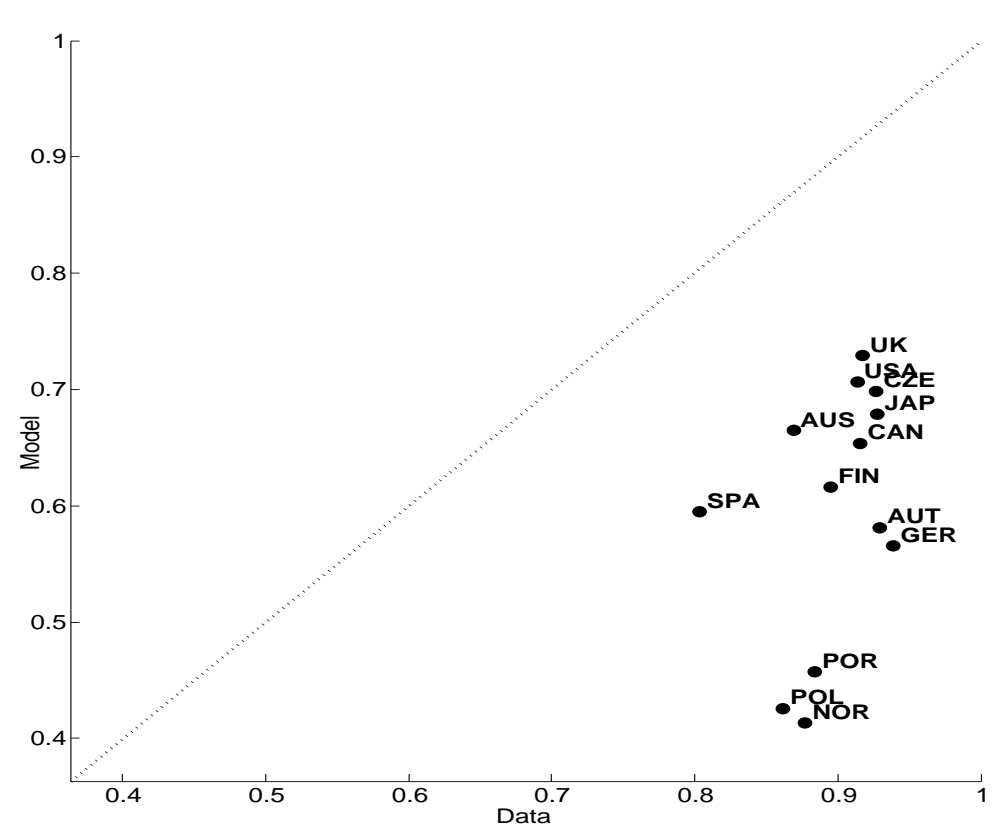


Figure 6: Unemployment-productivity correlation

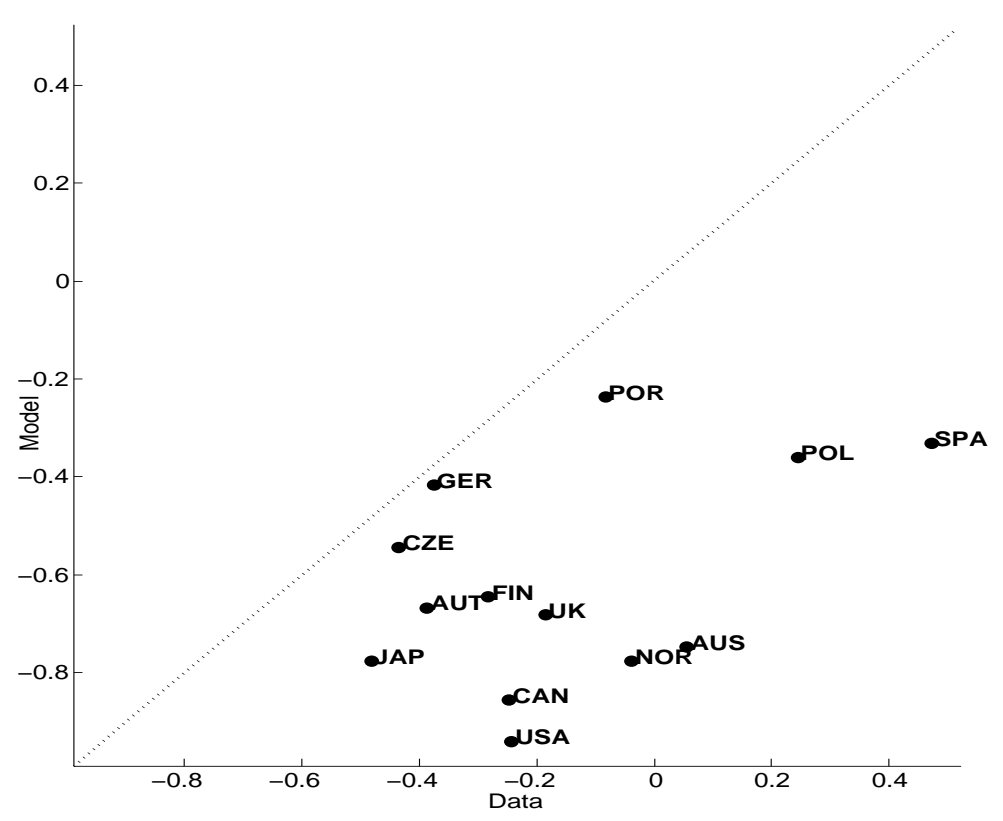

Figure 7: Unemployment-vacancies correlation

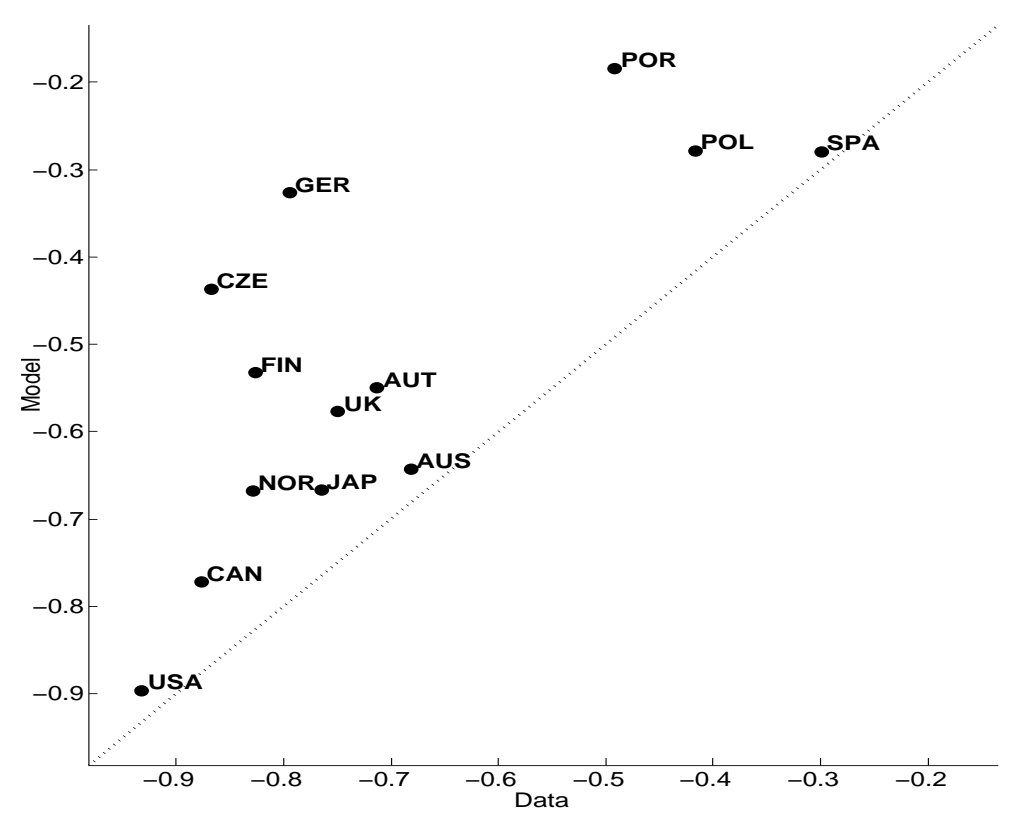


Table 18: Australia (HM calibration)

\begin{tabular}{|c|c|c|c|c|c|c|c|c|c|}
\hline & \multicolumn{4}{|c|}{ Data } & \multicolumn{4}{|c|}{ Model } \\
\hline & & $\mathrm{u}$ & $\mathrm{v}$ & $\mathrm{v} / \mathrm{u}$ & $\mathrm{p}$ & $\mathrm{u}$ & $\mathrm{v}$ & $\mathrm{v} / \mathrm{u}$ & $\mathrm{p}$ \\
\hline \multirow{2}{*}{\multicolumn{2}{|c|}{$\begin{array}{l}\text { Std. Dev. } \\
\text { Autocorr. }\end{array}$}} & 0.095 & 0.165 & 0.240 & 0.010 & 0.108 & 0.202 & 0.268 & 0.010 \\
\hline & & 0.907 & 0.869 & 0.903 & 0.719 & 0.879 & 0.582 & 0.713 & 0.719 \\
\hline \multirow{4}{*}{ Correlation } & $\mathrm{u}$ & 1 & -0.681 & -0.864 & 0.056 & 1 & -0.440 & -0.734 & -0.740 \\
\hline & $\mathrm{v}$ & - & 1 & 0.957 & 0.230 & - & 1 & 0.932 & 0.905 \\
\hline & $\mathrm{v} / \mathrm{u}$ & - & - & 1 & 0.136 & - & - & 1 & 0.981 \\
\hline & $\mathrm{p}$ & - & - & - & 1 & - & - & - & 1 \\
\hline
\end{tabular}

Dates: Q2-1979: Q2-2011

Table 19: Austria (HM calibration)

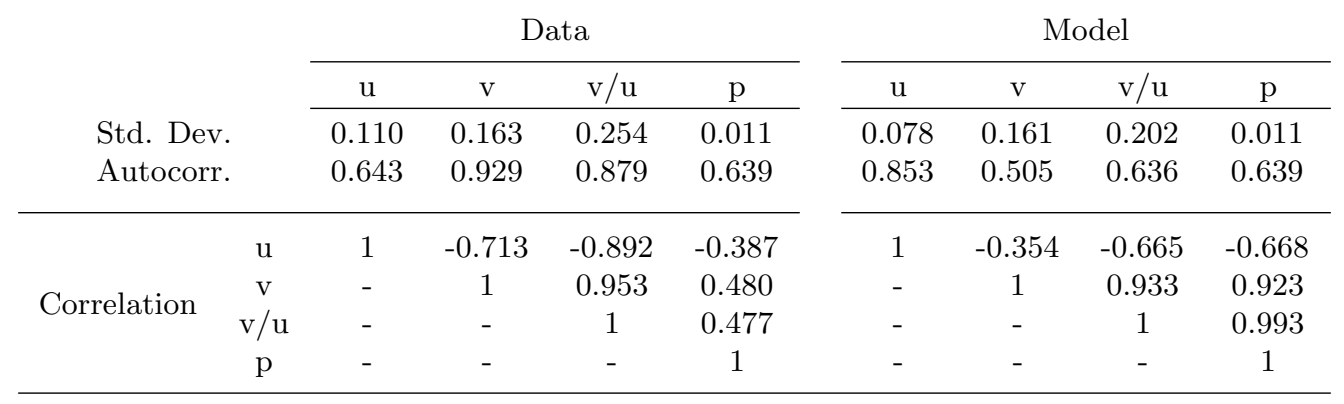

Dates: Q1-1969: Q2-2011

Table 20: Canada (HM calibration)

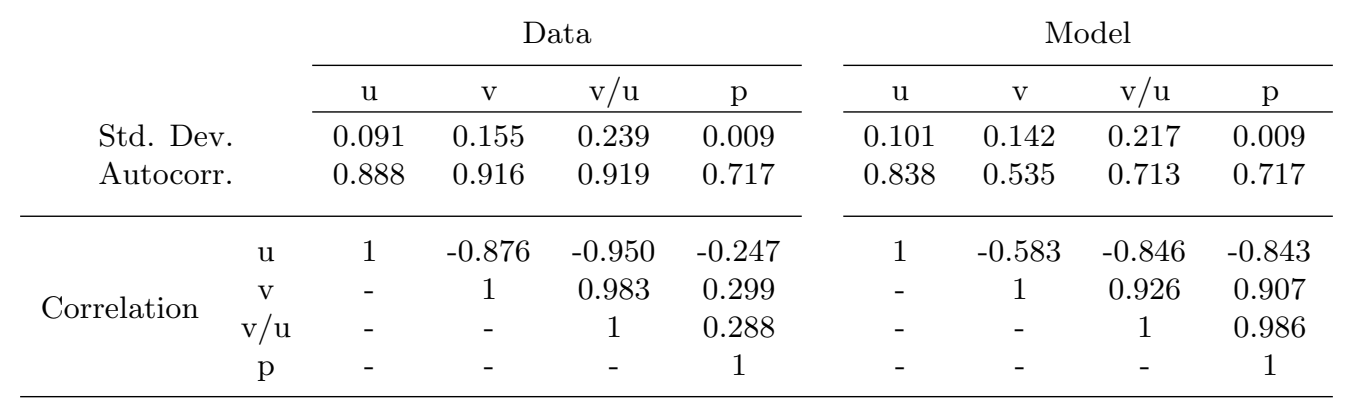

Dates: Q1-1962: Q2-2011 
Table 21: Germany (HM calibration)

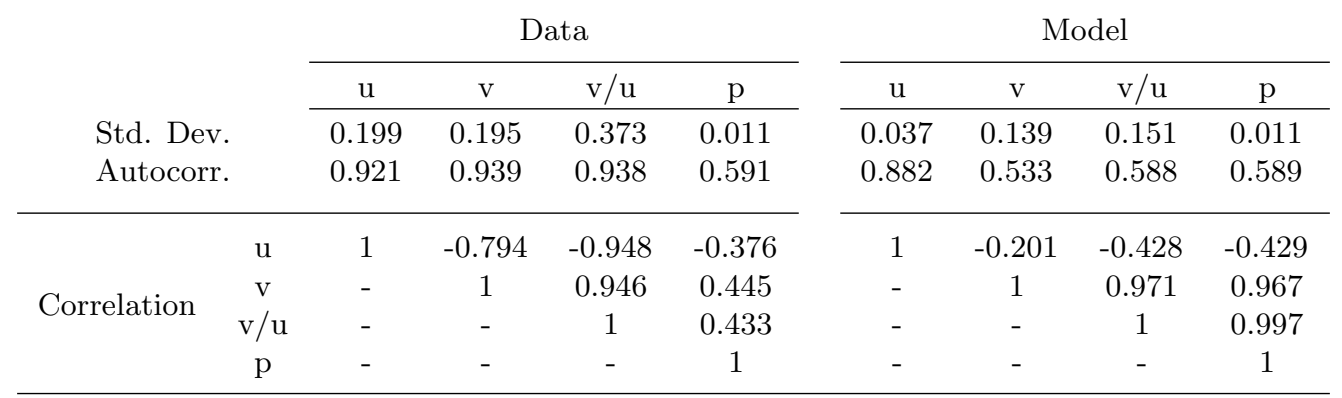

Dates: Q1-1962: Q2-2010

Table 22: Japan (HM calibration)

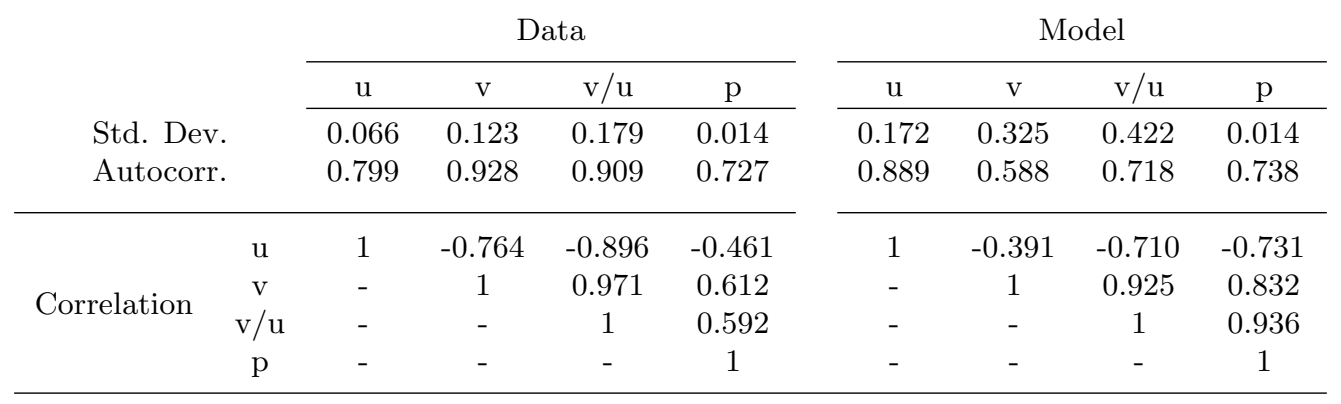

Dates: Q2-1967 : Q2-2011

Table 23: Portugal (HM calibration)

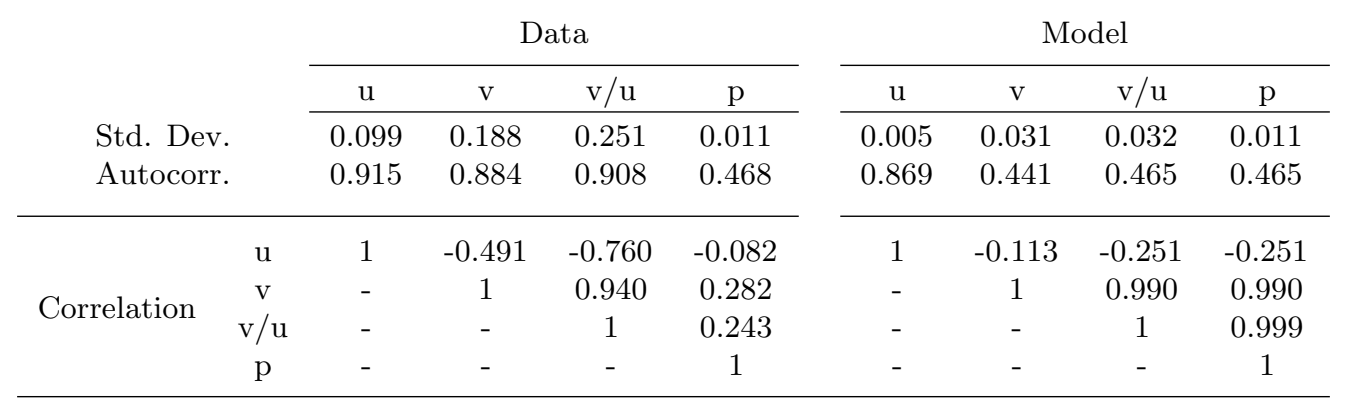

Dates: Q2-1983: Q2-2011 
Table 24: Spain (HM calibration)

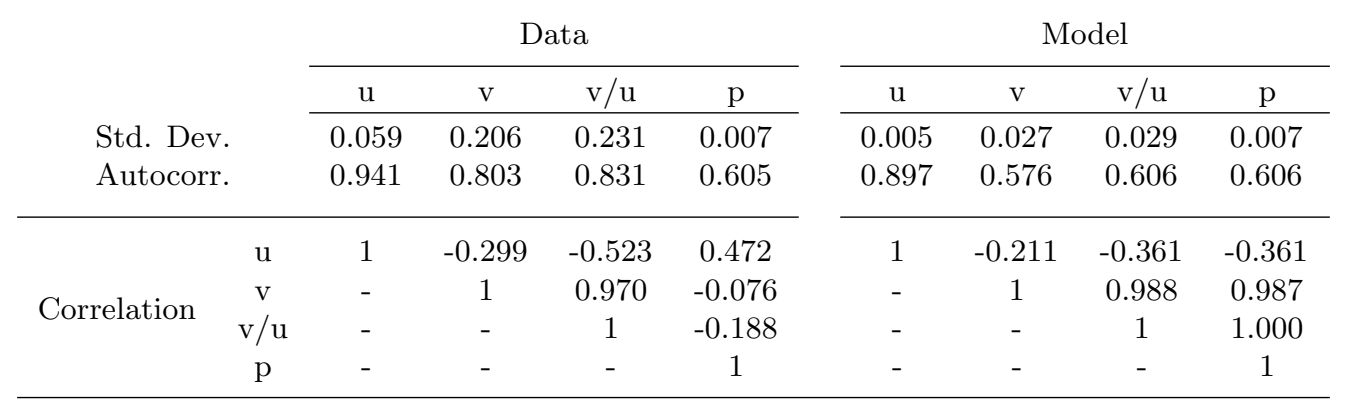

Dates: Q1-1977: Q1-2005

Table 25: U.K. (HM calibration)

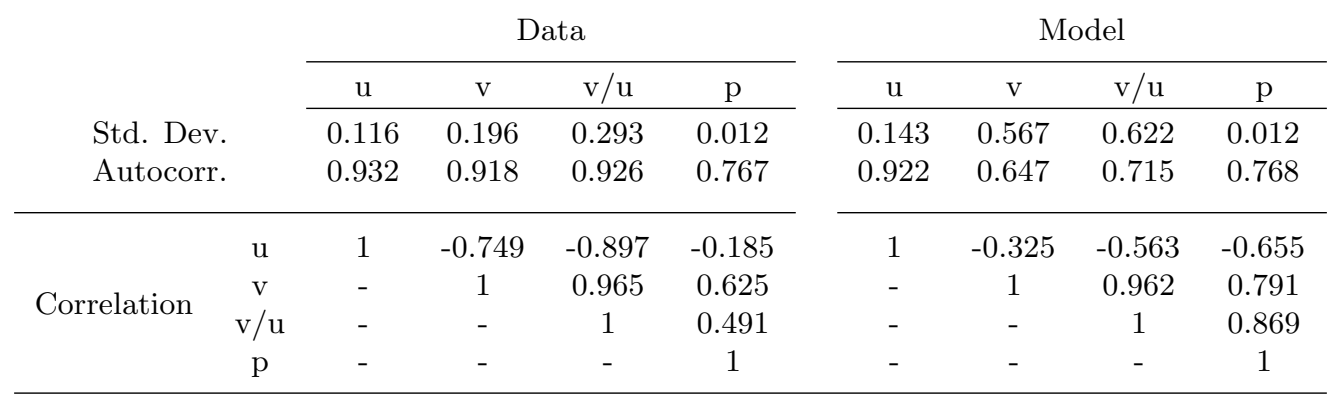

Dates: Q1-1971: Q2-2011

Table 26: U.S. (HM calibration)

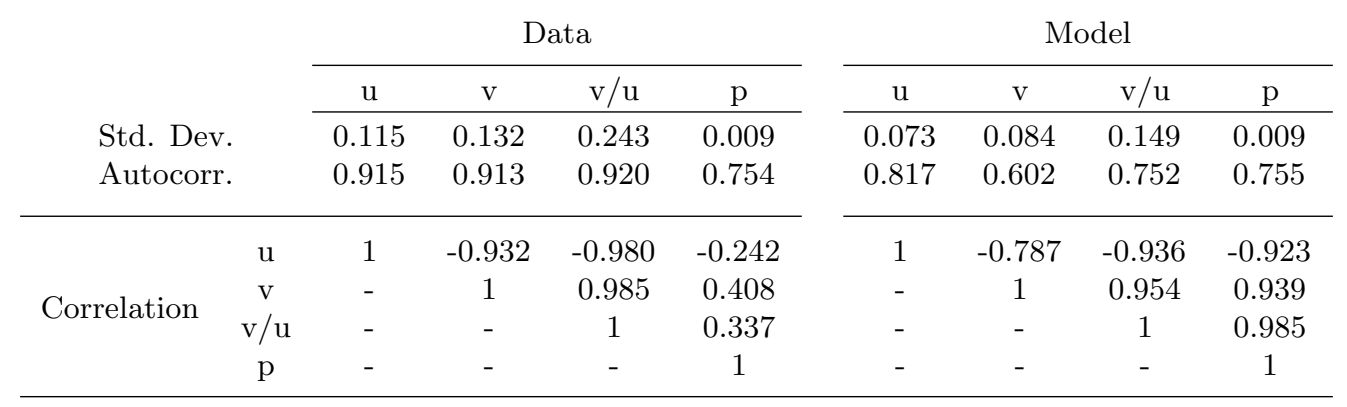

Dates: Q1-1960 : Q2-2011 
Figure 8: Sensitivity analysis
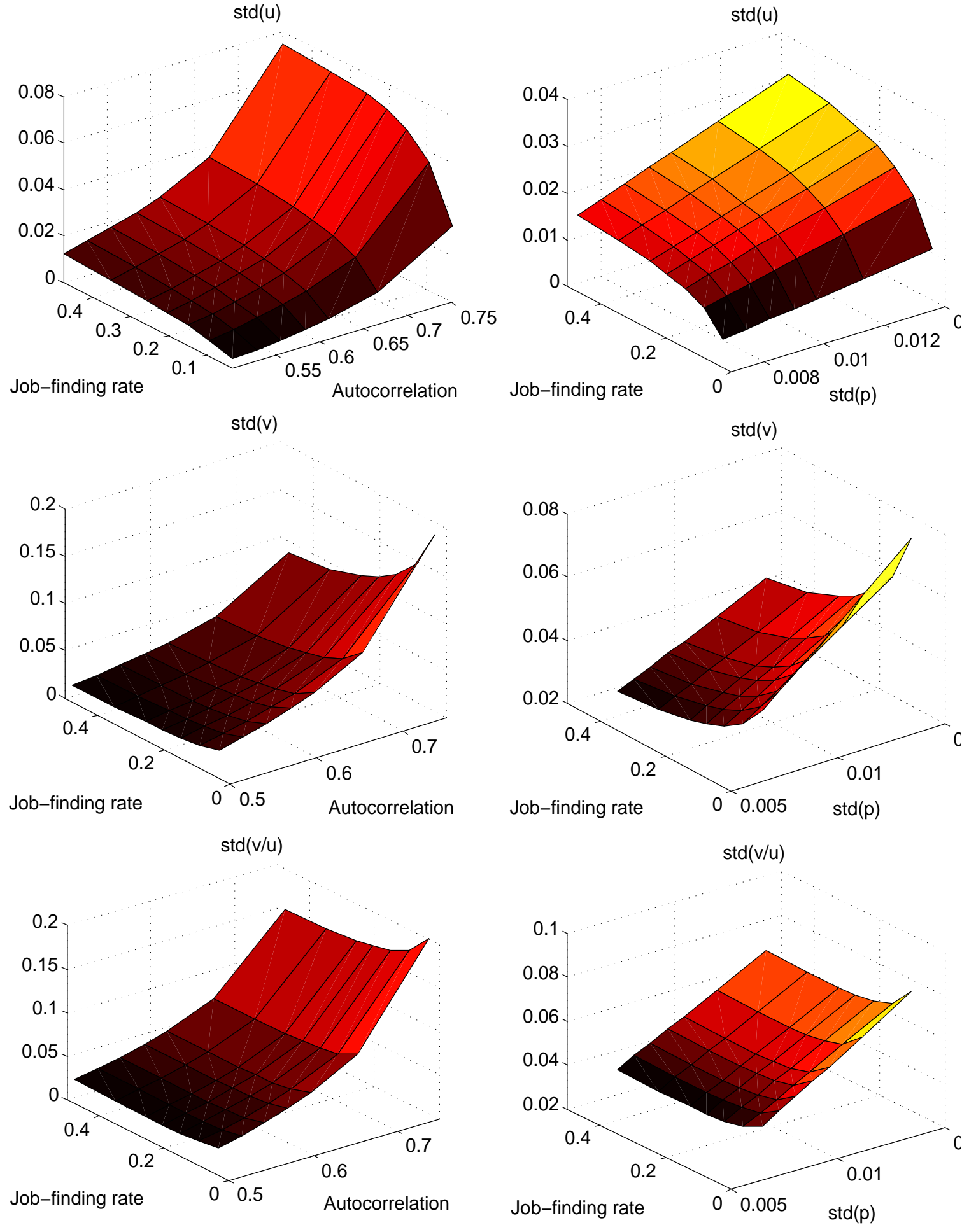
Figure 9: Impulse response: vacancies

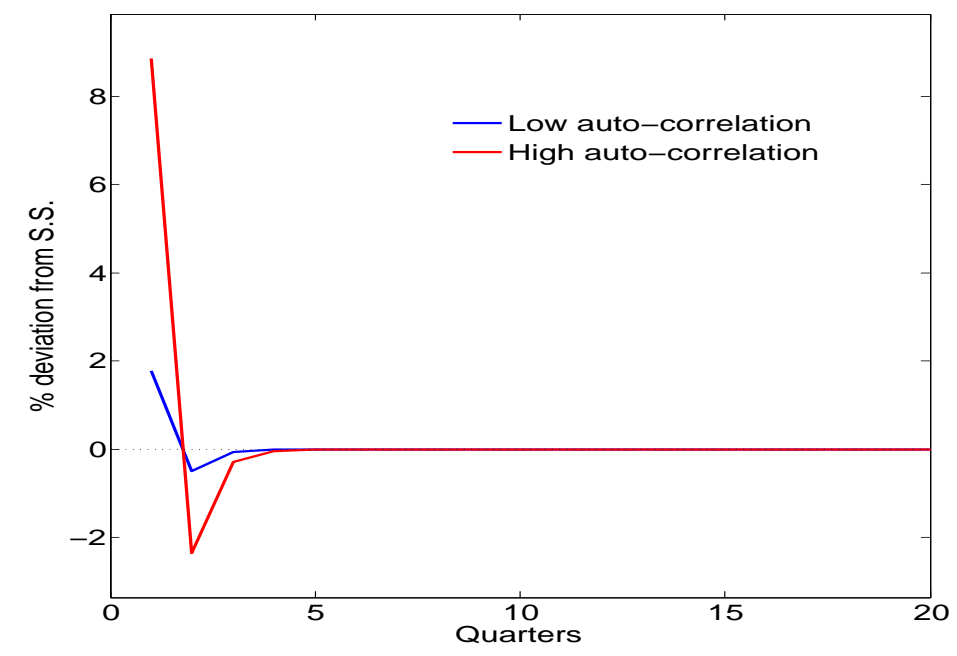

Figure 10: Impulse response: unemployment

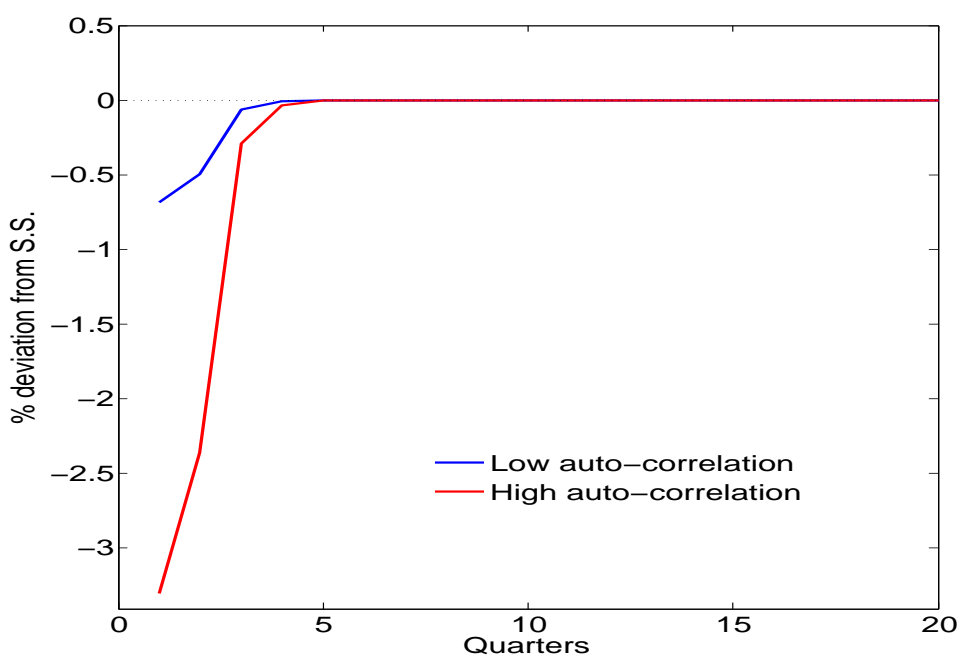


Figure 11: Unemployment autocorrelation (HM calibration)

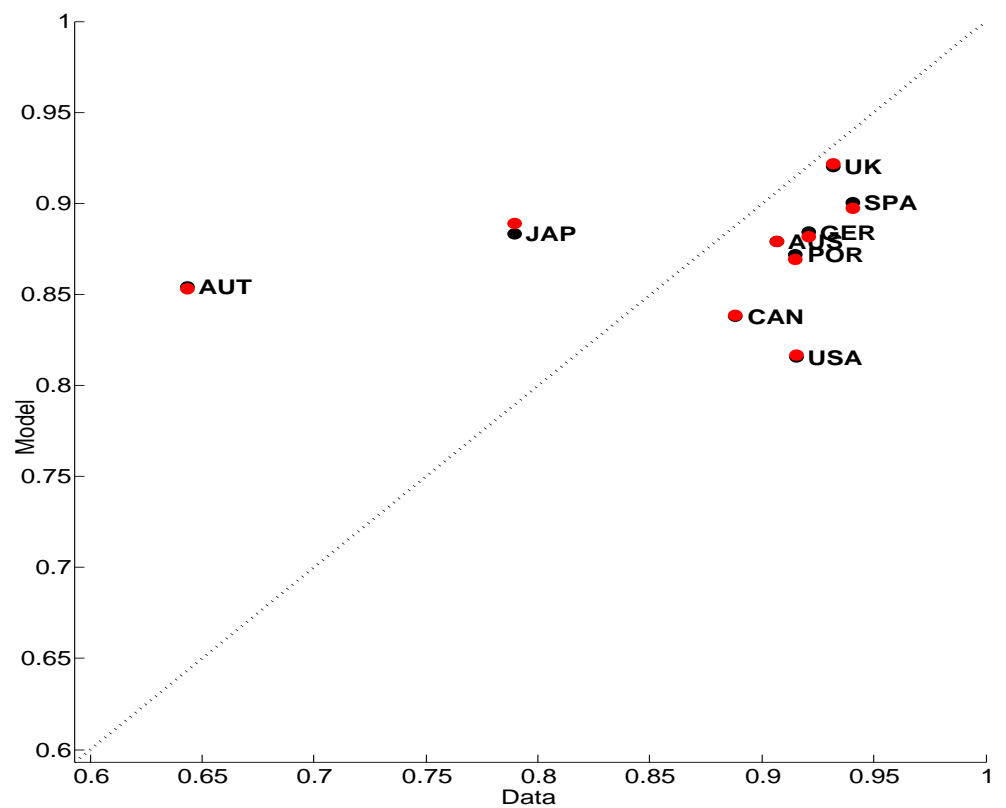

Figure 12: Vacancies autocorrelation (HM calibration)

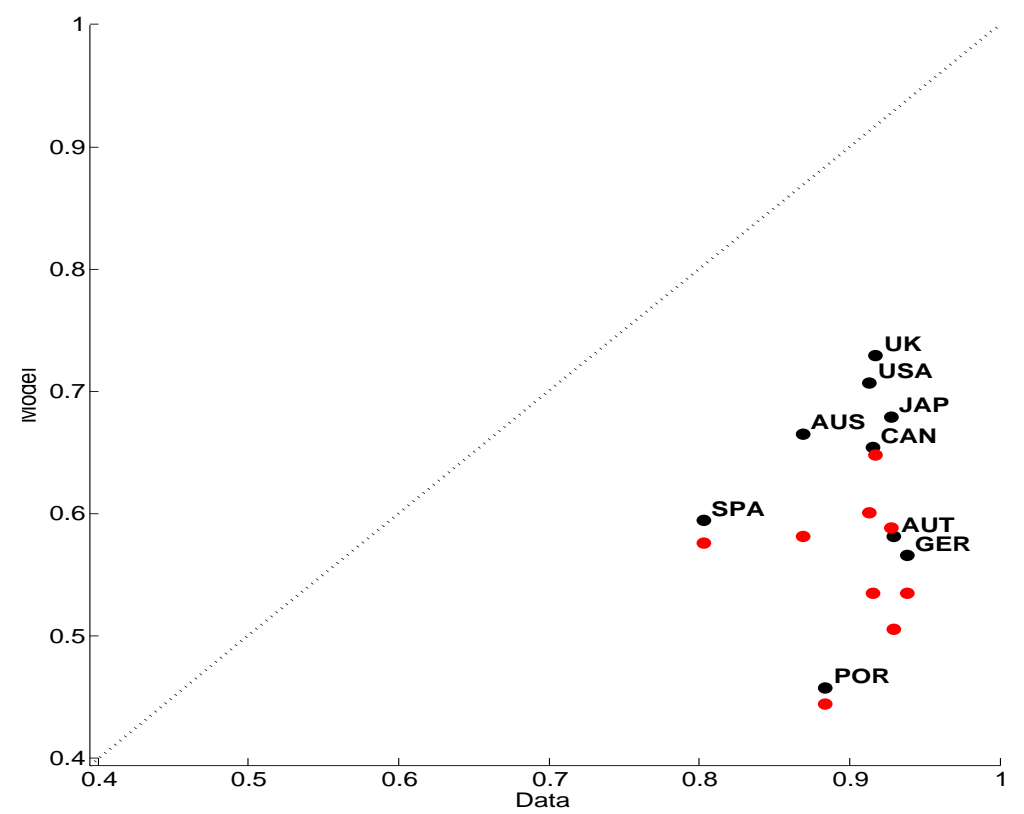


Figure 13: Unemployment-productivity correlation (HM calibration)

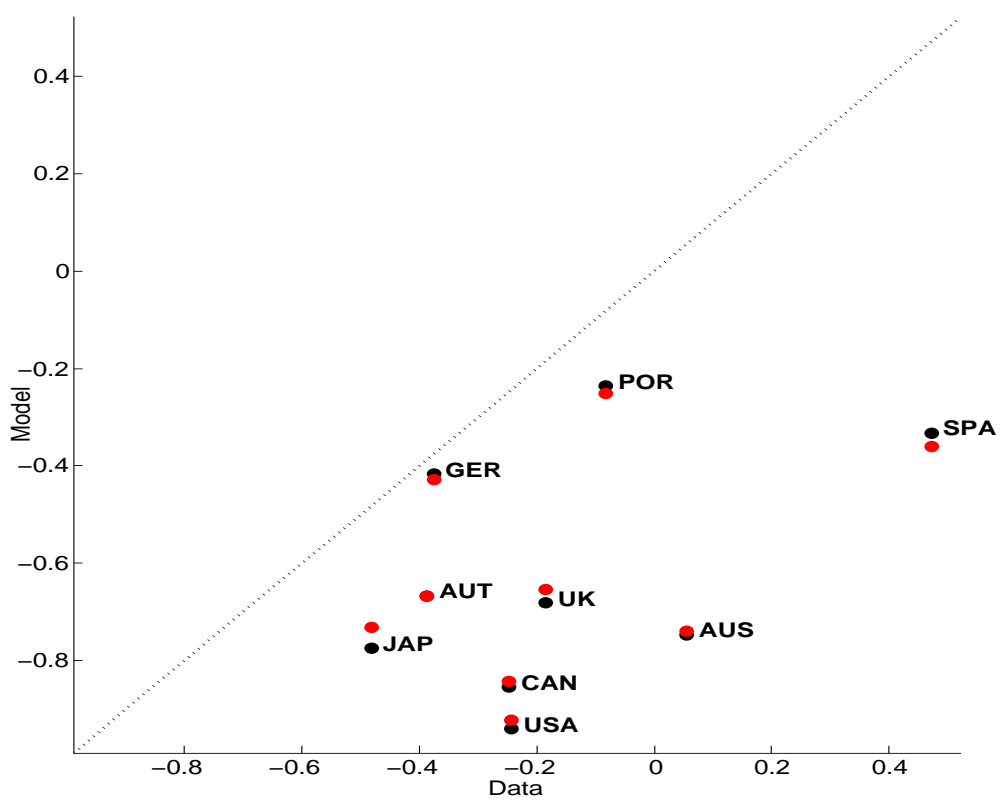

Figure 14: Unemployment-vacancies correlation (HM calibration)

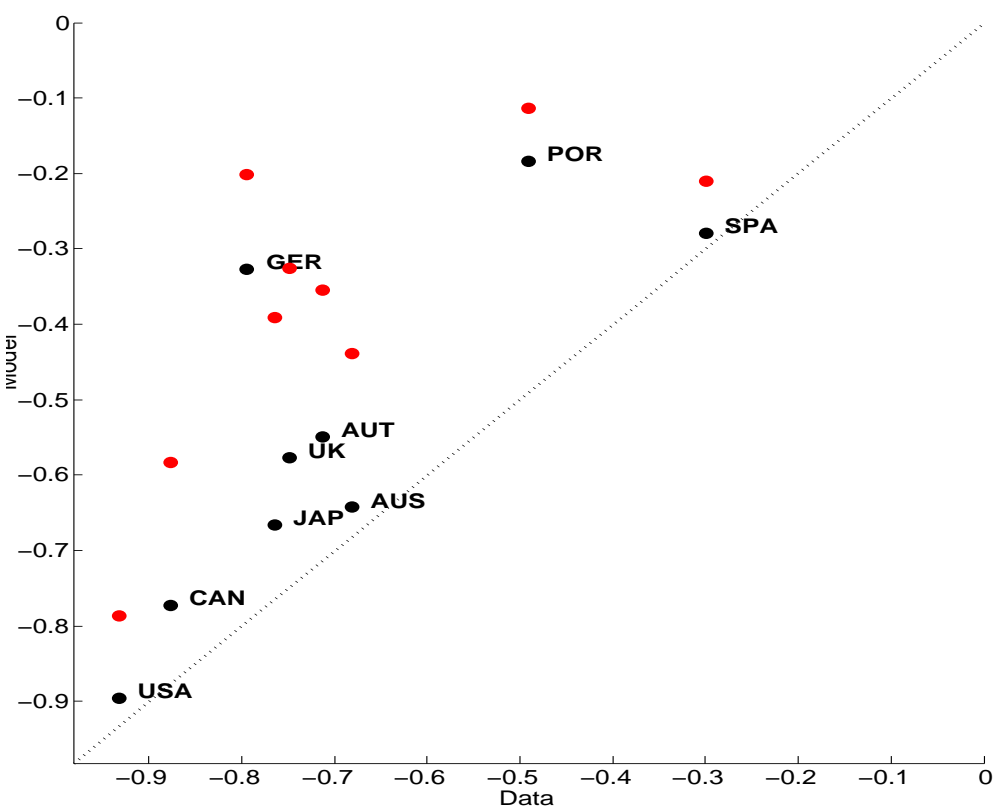

